\title{
EL TRIBUNAL CONSTITUCIONAL FEDERAL ALEMÁN ENTRE PROTECCIÓN JURÍDICA Y EXCESO COMPETENCIAL. SOBRE LA EFICACIA DE LOS CONTROLES CONSTITUCIONALES NACIONALES EN TIEMPOS DE CRISIS EUROPEA
}

\author{
MATTIAS WENDEL ${ }^{1}$ \\ Catedrático de Derecho Público \\ Universidad de Friburgo
}

\begin{abstract}
SUMARIO
I. Introducción. II. El marco procesal del control constitucional nacional. III. El marco procesal del TJUE: la judicial distribución de tareas en un sistema multinivel. IV. El nivel de control y los criterios de control. V. Conclusión y perspectiva.
\end{abstract}

\section{INTRODUCCIÓN}

Europa está dominada por la crisis. En la persistente crisis de los refugiados, en un debate social cada vez más polarizado, chocan posturas contrapuestas sobre la forma y el alcance de la protección humanitaria así como sobre la necesaria corresponsabilidad en Europa al respecto. Europa viene conteniendo la respiración durante casi una década de crisis económica y financiera. El déficit estructural de la Unión Económica y Monetaria (UEM) ha alcanzado una dimensión constitucional.

La crisis sitúa al Derecho ante importantes pruebas de fuego. Esto es así, especialmente, en el caso del Derecho constitucional en su dimensión nacional y europea. Si la Unión Europea quiere dar a conocer su modelo constitucional de Comunidad

1 Dr. Mattias Wendel, Doctor en Derecho (Paris 1) está Habilitado en el Walter-Hallstein-Institut für Europäisches Verfassungsrecht, Universidad Humboldt de Berlin. Desde el Semestre de invierno 2016/17 dirige la Cátedra de Derecho público en la Universidad de Friburgo. Versión al castellano de la Prof. Dra. D. ${ }^{2}$ Mónica Arenas Ramiro, Profesora Contratada Doctora de Derecho constitucional de la Universidad de Alcalá 
jurídica ${ }^{2}$, el Derecho debe también, incluso durante la crisis, no retroceder ante lo estrictamente necesario ${ }^{3}$. Los más altos portavoces judiciales, esto es, a nivel comunitario, el Tribunal de Justicia de la Unión Europea (TJUE) y, a nivel nacional, los Tribunales Constitucionales y Supremos, juegan aquí un papel destacado. La revisión judicial y la correspondiente garantía del Estado de Derecho constituyen un valor fundamental, en tanto que son medidas adecuadas formuladas conforme a categorías jurídicas. El control judicial debe, y puede, realizarse sólo en relación con el Derecho sustantivo, cuyo cumplimiento se dirige a controlar. De otra forma, se depositarían en el Derecho expectativas irrealizables, las cuales desembocarían, en el mejor de los casos, en decepción, y, en el peor de los casos, en una desconfianza general frente al, supuestamente, impotente Estado de Derecho. Esto sucede también cuando, como ha ocurrido frecuentemente durante la crisis, los más altos órganos judiciales son llamados a decidir. A través de ellos se concretarán normas jurídicas esenciales, a menudo no detalladas ${ }^{4}$, de vez en cuando, también, sobrecargadas.

Con vistas a las correspondientes normas jurídicas, la Liga constitucional europea $^{5}$ se caracteriza por una peculiaridad. En virtud de su esencial estructura constitucional pluralista ${ }^{6}$ se construirán criterios jurídicamente vinculantes en el mismo sentido plural, esto es, tanto a nivel constitucional europeo como a nivel constitucional nacional. Por consiguiente, ante los Tribunales los efectos de la crisis no se producen sólo en ámbitos de control bien diferenciados, sino que, de vez en cuando, se producen en ámbitos o niveles de control concurrentes unos con otros. Sin duda, estos ámbitos de control no se encuentran aislados unos de otros. Más bien, son los diferenciados ordenamientos jurídicos del Derecho comunitario y de los Derechos constitucionales nacionales, los obligados formalmente a través de estructuras normativas permeables ${ }^{7}$, así como sensibles $^{8}$, a una inclusión y una aceptación de los «otros» ${ }^{9}$. La cuestión es que la medida de la legalidad empleada

2 Respectivamente «Unión jurídica». Véase, TJUE C-362/14 (Schrems), EU:C:2015:650, Apdo. 60.

3 Sin embargo, un retroceso de este tipo constatan Hufeld, U., «Zwischen Notrettung und Rütlischwur», en Integration, 2011, pp. 117 y ss., 122; SCHORKOPF, F., «Gestaltung mit Recht», en AöR, 136/2011, pp. 323 y ss., 341 y ss.; C. Joerges, «Europas Wirtschaftsverfassung in der Krise», en Der Staat, 51/2012, pp. 357 y ss., 378-381, con más referencias.

4 Crítico con respecto al BVerfG, Lepsius, O., «Die maßstabsetzende Gewalt», en Jestaedt y otros (Ed.), Das entgrenzte Gericht, 2011, pp. 159 y ss., 227 y ss.

5 Fundamental, Pernice, I., «Bestandssicherungen der Verfassungen», en Bieber / Widmer (Eds.), L'espace constitutionnel européen, 1995, pp. 225 y ss., 233 y ss.; del mismo, «Europäisches und nationales Verfassungsrecht», en VVDStRL, 60/2001, pp. 148 y ss.; del mismo, «Theorie und Praxis des Europäischen Verfassungsverbundes», en CALliEss C. (Ed.), Verfassungswandel im europäischen Staaten- und Verfassungsverbund, 2007 , pp. 61 y ss., con más referencias a la recepción y crítica de los conceptos.

6 Más próximo, MAYER, F.C., «Verfassung im Nationalstaat: Von der Gesamtordnung zur europäischen Teilordnung?», en VVDStRL, 75 (2016), p. 7 (38 y ss.), con numerosas referencias.

7 Para el concepto, Wendel, M., Permeabilität im europäischen Verfassungsrecht, 2011, pp. 7 y ss.

8 Véase, Viellechner, L., «Responsiver Rechtspluralismus», en Der Staat, 2012, p. 559 (569 y ss.).

9 Véase, también, Fischer-Lescano, A., «Monismus, Dualismus? - Pluralismus. Selbstbestimmung des Weltrechts bei Hans Kelsen und Niklas Luhmann», en BrunkHorst H. / Voigt R. (Ed.), RechtsStaat, 2007, pp. 203 y ss. 
entre los más altos Tribunales difiere en los diferentes niveles, por lo que, en este punto, no debe crearse un riesgo para la estructura constitucional europea en su conjunto. Su potencial de mutua estabilización puede, bajo tales circunstancias, desarrollarse plenamente a través de un nivel de tensión federal —así previsto, dicha tensión será procesada de forma constructiva.

Precisamente, la crisis económica y financiera permite ser contada, desde todos los puntos de vista, como un tipo de relato sobre el nivel de tensión federal. En el año 2012, con el anunciado Programa sobre «Operaciones Monetarias sin Restricciones (en España, de Compraventa)» $(\mathrm{OMC})^{10}$ del Banco Central Europeo (en adelante, BCE), el recurso a medidas no convencionales para superar esta crisis se presentó como algo paradigmático. Su enérgico anuncio a través del Presidente del BCE, Draghi, vino a ser algo equivalente a una presunción de exceso de autocomplacencia. La hasta ahora eufórica expresión «lo que sea necesario» ${ }^{11}$ sugería, nada menos, que la primacía de hacer efectiva la necesidad. Y así se consiguió, sólo a través de esta sugerencia, la deliberada y buscada «estabilización» del mercado, sin que fuera necesaria ni una sola medida de ejecución ${ }^{12}$.

Con dudas sobre la legitimidad de este Programa, el Tribunal Constitucional Federal alemán (en adelante, por sus siglas en alemán, BVerfG (Bundesverfassungsgericht)) tomó, en el año 2014, por primera vez en su historia, la decisión de recurrir al Tribunal de Justicia de la Unión Europea (TJUE) en el marco de un procedimiento prejudicial ${ }^{13}$. La interpretación del Segundo Senado marcó un paso decisivo en la jurisprudencia sobre el proceso de integración que venía elaborando el Tribunal de Karlsruhe. En realidad, el BVerfG ya había demostrado con anterioridad su disposición para acudir al TJUE ${ }^{14}$. Pero, a diferencia, por ejemplo, del Tribunal Constitucional español ${ }^{15}$, o del Consejo Constitucional

10 El Programa se menciona en una Nota de Prensa publicada el 6.9.2012, pero hasta la fecha no se ha publicado la Decisión del Consejo del BCE. A través de él se ha establecido un marco general de condiciones para una potencial compra ilimitada de determinados bonos del Estado de los Estados miembros seleccionados en el mercado secundario. Conforme al Protocolo de la sesión 340 del Consejo del BCE de 5./6.9.2012 es reproducido el contenido de la Decisión sólo en esa Nota de Prensa. No hay un texto independiente, que se anexara formalmente en la Decisión. Compárese TJUE, T-492/12 (Storch y otros/BCE), EU:T:2013:702, Apdo. 2.

11 La declaración proviene de uno de los anuncios del Programa OMC, previamente manifesta por M. Draghi con motivo de la Conferencia «Global Investment», celebrada en Londres el 26.7.2012: «Within our mandate, the ECB is ready to do whatever it takes to preserve the Euro. And believe me, it will be enough».

12 Hoy en día, el Programa OMC no se ha retirado formalmente, pero sin embargo, posiblemente, todavía tengo efectos de fondo. Con su activación no se espera mucho más. Sin embargo, se puso en práctica una Quantitative Easing, retitulada oficialmente como «Programa Expandido de Compra de Activos» (siglas en inglés, EAPP). Una diferencia principal con el Programa OMC, es que el EAPP no es selectivo, es decir, no sólo se aplica para los individuales bonos del Estado de los Estados miembros seleccionados. No sólo visto este gran atractivo, sino también, a la vista de los objetivos perseguidos, el EAPP debe ser considerado como un aliud al OMC.

13 BVerfG, Decisión de 14.1.2014, BVerfGE 134, 366 (OMC-Petición).

14 Especialmente BVerfGE 125, 260 (308), Apdo. 185 y ss. - Retencion de datos personales.

15 La propuesta condujo al TJUE, Sentencia de 26.2.2013 - C-399/11 — Melloni. Con detalle, Torres Pérez, en EuConst, 2012, pp. 105 y ss. 
Francés (Conseil Constitutionnel) ${ }^{16}$, el BVerfG ha dejado sin aprovechar, hasta la fecha, todas las oportunidades que ha tenido disponibles ${ }^{17}$. Con la consulta sobre el OMC el diálogo entre ambos Altos Tribunales entró en una nueva fase. Se puede decir que, en general, fue tan oportuno y bien recibido el hecho de una petición presentada por medio del BVerfG, como, sin embargo, en especial, pareció cuestionable la petición presentada sobre el Programa OMC. El procedimiento constitucional principal está basado, esencialmente, en un denominado control ultra-vires, en cuyo marco, el BVerfG —en contra del garantizado monopolio interpretativo comunitario del TJUE- hace uso de una decisión final sobre la cuestión de la (evidente) incompetencia de las acciones de los órganos comuni$\operatorname{tarios}^{18}$. Mediante la cuestión prejudicial planteada el BVerfG, en esencia, quería saber confirmada su propia opinión jurídica, según la cual el Programa OMC, primero, excedía el mandato del Derecho originario del BCE y, segundo, había contravenido el art. 123 TFUE. Aunque en su Sentencia del año 2015 sobre el caso Gawweiler y otros ${ }^{19}$, el TJUE no compartió, en un amplio porcentaje, la opinión jurídica del BVerfG, se puede decir que el Tribunal de Justicia promulgó una sentencia que sería finalmente aceptada por el BVerfG en su Sentencia definitiva en el año $2016^{20}$. El reto de un control nacional ultra-vires, al que se enfrentó el garantizado monopolio interpretativo comunitario del TJUE tuvo, de este modo, como resultado final una solución conciliadora.

Una reflexión más detallada de la interacción dialógica entre el Tribunal Constitucional Federal alemán de Karlsruhe y el Tribunal de Justicia de la Unión Europea de Luxemburgo admite posteriores conclusiones a la pregunta sobre la eficacia de los controles constitucionales nacionales en los tiempos de crisis europea. En este sentido, la siguiente aportación se centra en la (hasta la fecha, única) petición del BVerfG y, con ella, en la apertura del procedimiento prejudicial en el caso OMC, pero, al mismo tiempo, se intenta situar esta jurisprudencia en el contexto más amplio de la producida crisis jurisprudencial a nivel nacional y comunitario. Junto al Tribunal Constitucional Federal, muchos otros Tribunales Constitucionales y Supremos se plantearon la constitucionalidad de las medidas de la crisis y, respectivamente, de sus esperadas consecuencias nacionales ${ }^{21}$. Ellos

16 Propuesta conjunta al TJUE, Sentencia de 30.5.2013 - C-168/13 - PPU - Jeremy F. Al respecto, WaLter, M., Verfassungsblog, de 15.3.2013.

17 En especial, BVerfGE 113, 273 - Europäischer Haftbefehl; BVerfGE 125, 260 (308), Apdo. 185 y ss. - Retención de datos personales; BVerfG, Sentencia de 24.4.2013, 1 BvR 1215/07, Apdo. 88-91 — Bases de datos contra el terrorismo.

18 Para la definición, fundamental, MAYER, F., Kompetenzüberschreitung und Letztentscheidung, 2000, p. 11.

19 TJUE, C-62/14 (Ganweiler y otros), EU:C:2015:400.

20 BVerfG, Sentencia de 21.6.2016, 2 BvR 2728/13, entre otras (Sentencia final caso OMC). A pesar de las considerables críticas a la argumentación del TJUE (compárese, especialmente, Apdos. 182-189) no se reconoció un acto ultra-vires o una violación de la identidad constitucional.

21 Análisis comparable, por FABBrini, «The Euro-Crisis and the Courts», en Berkeley Journal of International Law 2014, en detalle; y FAHEY/BARdutZky, «Judicial Review of Eurozone Law», en MJIL, 2013, p. 101 (105 y ss.). 
ilustran la diversidad de enfoques constitucionales y de los problemas producidos en el contexto de la crisis. A nivel europeo el TJUE, por su parte, fijó unos nuevos criterios con su importante decisión en el caso Pringle $e^{22}$, y de los cuales partieron tanto el propio Tribunal de Justicia como el BVerfG en el caso OMC.

La comprensión de la crisis de la Judicatura planteada por parte del BVerfG y su consideración en el contexto más amplio de la eficacia del Derecho constitucional en tiempos de crisis presupone un profundo debate sobre los fundamentos jurídicos procesales de esta jurisprudencia, lo que es también válido, al mismo tiempo, para entenderlo en el Derecho comparado (vid. II). Situando la relación dialógica entre el BVerfG y el TJUE en el punto de mira, se plantea igualmente válido aquí analizar el marco jurídico procesal en el TJUE (vid. III). A continuación de esto, se analizan las normas jurídicas materiales tanto del TJUE como del BVerfG, respectivamente, para considerar el nivel de control subyacente desde el punto de vista de una comparación integral, a todos los ámbitos de control (vid. IV). Tanto desde el punto de vista procesal, como también desde el material, se pone en evidencia, al mismo tiempo, el uso de un concedido, recíprocamente, margen de apreciación, como una técnica esencial combinada de un diálogo jurídico, el cual se basa en el respeto mutuo. Este análisis se transforma, finalmente, en una perspectiva del tema (vid. V).

\section{EL MARCO PROCESAL DEL CONTROL CONSTITUCIONAL NACIONAL}

Por lo que se refiere al ordenamiento del marco procesal, se puede distinguir entre los respectivos objetos procesales y el procedimiento procesal constitucional alcanzado a aplicar.

\section{Objeto procesal}

Su objeto procesal, en relación con el procedimiento seguido en el caso OMC, se centró en la legalidad de las medidas contra la crisis de unos órganos comunitarios, concretamente del BCE. Para analizar esta cuestión, hay que diferenciar situaciones en las que las medidas nacionales desarrolladas contra la crisis constituyan el objeto del control constitucional.

La constitucionalidad de los pactos fiscales internacionales ${ }^{23}$, y, respectivamente, el consentimiento estatal para su ratificación, según el orden cronológico en

22 TJUE, C-370/12 (Pringle), EU:C:2012:756.

23 Tratado de Estabilidad, Coordinación y Gobernanza en la Unión Económica y Monetaria (Pacto Fiscal o TECG), de 2.3.2012, firmado por todos los actuales Estados miembros de la Unión Europea excepto por el Reino Unido y la República Checa. En vigor desde el 1.1.2013. 
el que han ido siendo declarados fue: el Comité constitucional finés ${ }^{24}$, el Tribunal Constitucional húngaro ${ }^{25}$, el Consejo Constitucional francés ${ }^{26}$, el BVerfG, en el marco de su apreciado — más allá de las fronteras alemanas_- procedimiento abreviado $^{27}$, el Tribunal Constitucional austriaco $(\mathrm{VfGH})^{28}$, así como, nuevamente, el BVerfG en el marco de la decisión sobre el asunto principal ${ }^{29}$. Se enfrentan con el control de constitucionalidad del Mecanismo de Estabilidad Europeo (MEDE) ${ }^{30}$ y de otros componentes del fondo de rescate (respectivamente, el consentimiento nacional a estos instrumentos), de nuevo en orden cronológico: el Comité Constitucional finés ${ }^{31}$, el alemán BVerfG en tres decisiones sucesivas — entre las que se encuentra, primero, sobre el Fondo Europeo de Estabilidad Financiera (FEEF) y la ayuda finaciera bilateral ${ }^{32}$, segundo, sobre el control parlamentario ${ }^{33}$, así como, tercero, sobre el alcance del derecho de información dentro del Parlamento ${ }^{34}$ _, el Tribunal Supremo de Estonia ${ }^{35}$, la Corte Suprema irlandesa ${ }^{36}$, y, de nuevo, el BVerfG en su ya mencionada resolución ${ }^{37}$, el austriaco $\mathrm{VfGH}^{38}$, el polaco $\mathrm{VfGH}^{39}$, así como, finalmente, de nuevo, el BVerfG en su decisión en el asunto principal ${ }^{40}$. Finalmente, hay procedimientos de control de constitucionalidad que tienen por objeto la constitucionalidad de las medidas de austeridad nacionales ${ }^{41}$. En este sentido, la

24 Comité constitucional finlandés, Dictamen de 4.12.2012, PeVL 37/2012 (Pacto Fiscal).

25 Tribunal Constitucional húngaro, Sentencia de 11.5.2012, n. ${ }^{\circ} 22 / 2012$ (Pacto Fiscal).

26 Consejo Constitucional francés, Decisión de 9.8.2012, n. ${ }^{\circ}$ 2012-653 DC (Pacto Fiscal).

27 BVerfG, Sentencia de 12.9.2012, BVerfGE 132, 195 (MEDE y Pacto Fiscal — Decisión rápida)

28 Tribunal Constitucional austriaco, Decisión de 3.10.2013, SV 1/2013-15 (Pacto Fiscal).

29 BVerfG, Sentencia de 18.3.2014, BVerfGE 135, 317 (MEDE y Pacto Fiscal — Decisión sobre el asunto principal).

30 Conseguido por todos los actuales euro-Estados, Tratado Constitutivo del Mecanismo Europeo de Estabilidad, de 1.2.2012, en vigor el 27.9.2012. El MEDE fue previamente el Fondo Europeo de Estabilidad Financiera (FEEF), una sociedad bajo las norms de Luxemburgo. El MEDE no se debe confundir con el Mecanismo Europeo de Estabilización Financiera (MEEF), que era un instrumento de la Unión Europea, aprobado por el Reglamento (UE) n. ${ }^{\circ}$ 407/2010, basado en el art. 122.2 TFUE.

31 Comité Constitucional finlandés, Dictamen de 14.6.2011, PeVL 1/2011 vp — (MEDE I) así como - conforme a la, entre otras, Decisión sobre las necesarias renegociaciones sobre el Tratado MEDE— Decisión de 8.12.2011, PeVL 22/2011 vp (MEDE II).

32 BVerfG, Sentencia de 7.9.2011, BVerfGE 129, 124 (Ayuda financiera a Grecia y FEEF).

33 BVerfG, Sentencia de 28.2.2012, BVerfGE 130, 318 (Neunergremium).

34 BVerfG, Sentencia de 19.6.2012, BVerfGE 131, 152 (Obligaciones de información — MEDE \& Pacto Euro-Plus)

35 Tribunal Supremo de Estonia, Sentencia de 12.7.2012, n. ${ }^{\circ}$ 3-4-1-6-12 — (MEDE). Traducción al inglés disponible en http://www.riigikohus.ee/?id=1347.

36 Corte Suprema irlandesa, Auto de remisión de 31.7.2012, [2012] IESC 47 (Pringle).

37 BVerfG, MEDE y Pacto Fiscal - Decisión rápida (Nota a pie 26). El presente procedimiento, con la legislación de acompañamiento, tomó la forma de la Ley de Finanzas-MEDE.

38 Tribunal Constitucional austriaco, Decisión de 16.3.2013, SV 2/12-18 - (MEDE).

39 Tribunal Constitucional polaco, Sentencia de 26.6.2013, K 33/12 — Decisión 2011/199. Una traducción al inglés está disponible en: http://trybunal.gov.pl/uploads/media/SiM_LI_EN_calosc.pdf(25.8.2015), pp. 295-366 incluídos los Votos particulares.

40 BVerfG, MEDE y Pacto Fiscal - Asunto principal (Nota a pie 28).

41 En detalle, Kilpatrick, C., «Constitutions, social rights and sovereign debt states in Europe: a challenging new area of constitutional inquiry», en EUI Working Paper LAW, 2015/34. 
línea jurisprudencial más destacada es quizá la del Tribunal Constitucional portugués, que durante varios años ha repetido el análisis de elementos de la Legislación presupuestaria portuguesa para explicar la inconstitucionalidad de las medidas ${ }^{42}$. También, las decisiones del Tribunal Supremo Administrativo griego tienen que ser mencionadas aquí en relación con la inconstitucionalidad de las medidas de austeridad de la crisis económica europea ${ }^{43}$.

\section{El procedimiento de control y su alcance}

Otra posterior clasificación viene, nuevamente, de la mano del marco procesal y del alcance del procedimento de control jurídico asociado a él.

a) El procedimiento de control procesal constitucional: perspectiva comparada

Desde hace ya algunos años, con motivo de las decisiones europeas sobre el Tratado de Lisboa ${ }^{44}$, se mostró que en Europa existía, a nivel nacional, una gran variedad y modelos de Derecho procesal constitucional. Hoy en día, todavía permanecen diferencias sistemáticas en relación con la existencia de una jurisdicción constitucional especializada ${ }^{45}$. Así, por ejemplo, los ordenamientos constitucionales de los Estados escandinavos no conocen una jurisdicción constitucional en sentido clásico, sino que asignan, especialmente, a los Parlamentos, la competencia sobre la evaluación y el control de constitucionalidad. Conforme a ello, es significativo en Finladia el papel del Comité de Derecho Constitucional ${ }^{46}$, cuyo control parlamentario previo, «ex-ante», de las propuestas legislativas, o respectivamente, de los proyectos internacionales, jugó un importante papel en el caso del MEDE e, incluso, facilitó, concretamente, una incorporación de los resultados del control en las negociaciones en curso ${ }^{47}$. En muchos Estados, la Constitución

42 En especial, Tribunal Constitucional portugués, Sentencia de 5.7.2012, n. ${ }^{\circ}$ 353/2012 (Ley de Presupuestos 2012); Sentencia de 5.4.2013, n. ${ }^{\circ}$ 187/2013 (Ley de Presupuestos 2013); Sentencia de 30.5.2014, n. ${ }^{\circ}$ 413/2014 (Ley de Presupuestos 2014). Resúmenes en ingles pueden encontrarse disponibles en la web del Tribunal constitucional portugués: http://www.tribunalconstitucional.pt/tc/en/acordaos/. Para un vistazo sobre la jurisprudencia del Tribunal Constitucional portugués, compárese, por todos, CanotilHo, M. / VIOLANTE, T. / LANCEIRO, R., «Austerity measures under judicial scrutiny: the Portuguese constitutional caselaw», en EuConst, 2015, pp. 155 y ss.

43 Tribunal Supremo Administrativo griego, Decisiones de 10.6.2015, 2287-2290/2015 (Medidas de ahorro en las Leyes 4051/2012 y 4093/2012).

44 Véase, Wendel, M., «Lisbon Before the Courts», en EuConst, 2011, pp. 96 y ss., 102 y ss.

45 Un análisis de Derecho comparado puede verse en VISSER M. DE, Constitutional Review in Europe, 2013, pp. 11 y ss.

$46 \mathrm{Al}$ respecto, OJanen, T., «The Impact of EU Membership on Finnish Constitutional Law», en EPL, 2004, pp. 531 y ss., 532.

47 Compárese Tuori, K. / Tuori, K., The Eurozone Crisis - A Constitutional Analysis, 2014, pp. 195 y ss. 
atribuye, además, a los Tribunales Constitucionales o Cortes Supremas la competencia para controlar de forma preventiva los Tratados, es decir, la revisión de la constitucionalidad ex ante de los Tratados internacionales negociados. Este tipo de procedimientos llegaron a raíz de la crisis económica y financiera para aplicarse en Francia ${ }^{48}$, Estonia ${ }^{49}$ y Hungría ${ }^{50}$. En algunos casos, la Constitución permite también, o sólo, un control de los Tratados ex post ${ }^{51}$. Esto ocurre, concretamente, en Austria, donde su Tribunal Constitucional, en dos decisiones del 2013, desestimó las demandas presentadas para declarar la inconstitucionalidad del Tratado del Mecanismo Europeo de Estabilidad (Tratado-MEDE) y de los Pactos fiscales, por considerarlas infundadas ${ }^{52}$. Pero sin embargo, en Polonia tuvo lugar el control de la constitucionalidad del mismo sólo después de la ratificación ${ }^{53}$. Asimismo, se plantean cuestiones constitucionales relacionadas con la crisis en el marco del conflicto entre órganos constitucionales, como muestra, entre otros, la Ley Fundamental alemana ${ }^{54}$.

\section{b) El carácter electoral del control ultra-vires sustanciado ante el BVerfG}

La mayoría de las decisiones más relevantes del BVerfG relacionadas con Europa tienen su origen en recursos de amparo, esto es, en recursos presentados por quejas de los ciudadanos a título individual.

aa) El carácter electoral del «recurso ante Europa»

La norma sustantiva clave que fundamenta una queja individual del tipo de un «recurso ante Europa» es el derecho de sufragio reconocido en el art. 38.1.1 GG. Para un espectador no especializado en Derecho constitucional alemán, esta construcción provocará, por lo menos, ante todo, un efecto de sorpresa. El

48 Consejo de Estado Francés, Pacto Fiscal (Nota a pie 25).

49 Tribunal Supremo de Estonia, MEDE (Nota a pie 34).

50 Tribunal Constitucional húngaro, Pacto Fiscal (Nota a pie 24). Al respecto, DojCsák, D., «Report on Hungary», en EUI (Ed.), Constitutional Change through Euro Crisis Law, IX.2.

51 Por supuesto, esto plantea, sin duda, el problema de una desintegración de la conseguida unión internacional en las relaciones exteriores y la potencial inconstitucionalidad a nivel interno.

52 Tribunal Constitucional austriaco, MEDE (Nota a pie 37), Apdos. 42-110; Tribunal Constitucional austriaco, Pacto Fiscal, Apdos. 38-102.

53 Tribunal Constitucional polaco, Decisión 2011/199 (Nota a pie 38). El procedimiento fue el acto nacional de aprobación de la Decisión comunitaria del Consejo Europeo 2011/199 para la inclusión del art. 136.3 TFUE. Esta fue la forma de que, indirectamente, el MEDE fuera objeto de revisión constitucional por el Tribunal Constitucional polaco.

54 BVerfG, Neunergremium (Nota a pie 32); BVerfG, Obligación de información - MEDE \& Pacto EuroPlus (Nota a pie 33). las Decisiones sobre el MEDE, así como sobre la presentación del caso OMC, se basaron también, aunque de forma más marginal, en un procedimiento de conflicto entre órganos. 
trasfondo es el siguiente: la línea jurisprudencial instaurada con el caso Maastricht considera admisible la presentación de una queja constitucional, de un recurso de amparo, basada en la violación del derecho de sufragio, siempre y cuando el demandante explique motivadamente que la esencia del principio democrático se ha visto lesionada a través de actos que desprovén de competencias al Parlamento federal alemán, y, por lo tanto, como consecuencia, al Parlamento no le quedan competencias de peso sustantivo ${ }^{55}$. La idea es que debería garantizarse la esencia del principio democrático, que se encuentra también protegido por la «cláusula de eternidad» del artículo 79.3 GG frente a las revisiones constitucionales, además de por la conocida «identidad constitucional», descrita por la Ley Fundamental. En otras palabras, coforme mantiene el BVerfG, el derecho de sufragio otorga a los ciudadanos el derecho a exigir del Parlamento, como núcleo duro de la identidad constitucional, que éste tenga capacidad de decidir sobre cuestiones sustanciales.

Con razón, en un primer momento, los más críticos con esta postura reclamaban una delimitación de los fundamentales tipos de procedimientos existentes y advertían de una posible expansión ilimitada de la acción popular ${ }^{56}$. A pesar de esto, en los últimos años el BVerfG se ha mantenido firme en su planteamiento ${ }^{57}$, e incluso ha efectuado ampliaciones parciales del mismo ${ }^{58}$. Sin embargo, hasta la petición del caso OMC, el criterio de presentación de estas quejas o recursos ante Europa, se encontraba vinculado al concepto de identidad constitucional, en el sentido del artículo 79.3 GG, concretamente, vinculado al garantizado, como inalterable, núcleo duro del principio democrático ${ }^{59}$. Como resultado de su pre-

55 BVerfG, Sentencia de 12.10.1993, BVerfGE 89, 155 - (Maastricht), Apdo. 62 y ss.; BVerfG, Sentencia de 30.6.2009; BVerfGE 123, 267 - (Tratado de Lisboa), Apdos. 175, 211, 216 y ss., 245 y ss.; BVerfG, Ayuda finaciera a Grecia y FEEF (Nota a pie 31), Apdo. 101; BVerfG, MEDE y Pacto Fiscal - Decisión rápida (Nota a pie 26), Apdo. 105.

56 Compárese, especialmente, Tomuschat, C., «Die Europäische Union unter der Aufsicht des Bundesverfassungsgerichts», en EuGRZ, 1993, pp. 489 y ss.; BRYDE, B.-O., Das Maastricht-Urteil des Bundesverfassungsgerichts — Konsequenzen für die weitere Entwicklung der europäischen Integration, 1993, pp. 4 y ss.; MEESSEN, K.M., «Maastricht nach Karlsruhe», en NJW, 1994, pp. 549 y ss., 550 y ss.; KöNIG, D., «Das Urteil des Bundesverfassungsgerichts zum Vertrag von Maastricht - ein Stolperstein auf dem Weg in die europäische Integration?», en Zä̈RV, 54/1994, pp. 17 y ss., 27 y ss.; GASSNER, U.M., "Kreation und Repräsentation — Zum demokratischen Gewährleistungsgehalt von Art. 38 Abs. 1 S. 1 GG», en Der Staat 34/1995, pp. 429 y ss., 439 y ss.; KLEIN, E., «Grundrechtsdogmatische und verfassungsprozessuale Überlegungen zur Maastricht-Entscheidung des Bundesverfassungsgerichts», en Gedächtnisschrift Grabitz, 1995, pp. 271 y ss.

57 Bajo el imaginable conflicto con la amplia crítica doctrinal, el BVerfG confirmó su trayectoria en su Decisión sobre el caso Ayuda financiera a Grecia y FEEF (Nota a pie 31), Apdos. 101 y ss. Afirmativamente se pronuncia KAHL, W., «Bewältigung der Staatsschuldenkrise unter Kontrolle des Bundesverfassungsgerichts», en DVBl. 2013, pp. 197 y ss., p. 207.

58 Con detalle, Ruffert, M., «Die europäische Schuldenkrise vor dem Bundesverfassungsgericht», en $E u R, 2011$, pp. 842 y ss., 844 y ss. Anteriormente ya se habían realizado ampliaciones, como en la Sentencia al caso Lisboa. Al respecto, Tнум, D., «Europäische Integration im Schatten souveräner Staatlichkeit», en Der Staat, 2009 , pp. 559 y ss., 560 y ss.

59 Conforme al BVerfG, Ayuda financiera a Grecia y FEEF (Nota a pie 31), Apdo. 101 y ss. debería poder garantizarse procesalmente a los ciudadanos un mecanismo contra una enajenación de competencias 
sentación, se abrió también, de facto, la puerta a un control previo de los Tratados en Alemania, donde la Constitución no prevé este tipo de control. Sobre la esencia o vinculación electoral de este tipo de quejas europeas, la misma radica en que cada ciudadano tiene la posibilidad de solicitar preventivamente su protección frente a un temido vaciamiento de las competencias del Parlamento que se pueda producir a través de una inminente cesión de soberanía (como puede suceder, por ejemplo, en el marco de una modificación de los Tratados).

\section{bb) El control ultra-vires}

En la saga de los pronunciamientos sobre el Programa OMC, el BVerfG añade un posterior elemento a su jurisprudencia sobre integración europea, el conocido control ultra vires. A este respecto, se trata de la consecuente pregunta relacionada con la cesión de soberanía, de si los órganos de la Unión se mantienen o no dentro del marco de las competencias transferidas por el Derecho originario. Para ello, el BVerfG afirmó, en contra del primario y predeterminado monopolio interpretativo del TJUE, un derecho de decisión final. El control ultra vires y sus requisitos procesales constitucionales son, hasta hoy, sólo producto de la jurisprudencia. El legislador se ha posicionado en contra de la invitación abierta por parte del $\mathrm{BVerfG}^{60}$ de estandarizar un procedimiento especialmente adaptado, por buenas razones, dado que podría ser finalmente contrario al Derecho comunitario. Pero no es nada nuevo que el BVerfG reclame para sí un derecho de decisión final en relación con los asuntos ultra vires ${ }^{61}$. Las primeras alusiones, realizadas de forma prudente, se encuentran ya en la jurisprudencia del año $1971^{62}$, seguido de unas señales más claras en los años $1981^{63}$ y $1987^{64}$. Ya abiertamente en la Sentencia del caso Maastricht de 1993 se afirmaba, por primera vez, una clase de reserva de comprobación de los actos jurídicos que desencadenaran el conflicto ${ }^{65}$. Más recientemente, después de la Sentencia al caso Lisboa de 2009, y a partir de ese momento, se concretaba la citada reserva de comprobación bajo el tópico del control ultra vires ${ }^{66}$.

incompatible con el art. 79.3 GG. Se privó permanentemente a los ciudadanos, a través de las obligaciones de los aspectos esenciales de una autodeterminación política, de sus posibilidades de influencia democrática, lo que llevaría a que, finalmente, la reclamación de la democracia por parte de los ciudadanos, ligado a la idea de dignidad humana, fuera inválida.

60 BVerfGE 123, 267 (355), Apdo. 241 - Lisboa.

61 Un exhaustivo análisis, en MAYER/WENDEL, «Die verfassungsrechtlichen Grundlagen des Europarechts», en Hatje/Müller-GrafF (Eds.), Enzyklopädie Europarecht, Band 1, 2014, Apdos. 239 y ss.; SAUER, H., Jurisdiktionskonflikte in Mehrebenensystemen, 2008, pp. 179 y ss.

62 BVerfGE 31, 145 (174) — Lütticke («im Rabmen seiner Kompetenz ... ergangene»).

63 BVerfGE 58, 1 (30 s.) - Eurocontrol I.

64 BVerfGE 75, $223(235,242)$ - Kloppenburg.

65 BVerfGE 89, 155 (187 s.) - Maastricht.

66 BVerfGE 123, 267 (353 s.), Apdos. 240 y ss. — Lisboa. 
En el caso Lisboa el BVerfG desarrolló la interpretación constitucional que ya había utilizado en el caso Maastricht relacionada con el principo de atribución de competencias. Esto es, entendiéndolo «no sólo como un principio fundamental del Derecho comunitario», sino más bien, como la consecuencia del «fundamento constitucional del poder de la Unión ${ }^{67}$, de un ordenamiento juridico que, a pesar de su autonomía funcional, no deja de ser un «ordenamiento jurídico derivado» ${ }^{68}$. En este sentido, el Derecho comuntario se ve reducido así, en contra de su postulado de autonomía normativa ${ }^{69}$, a un derivado de la regulación estatal ${ }^{70}$. Pero el concreto contenido de la Ley de aprobación o ratificación estatal sólo podrá apreciarse si se recurre a su punto de referencia, al Derecho primario europeo. De esta forma, el control ultra-vires dirigido a examinar el cumplimiento del previamente consentido proceso de integración no se limita solo, por lo tanto, a una verificación de la adecuación a las normas recogidas en la GG, sino que va a suponer, en contra del monopolio interpretativo del TJUE, una verificación al mismo tiempo del Derecho comunitario derivado y, en la misma medida, del Derecho originario.

El carácter híbrido de esta medida de revisión ${ }^{71}$, en tanto que comienza en Dercho constitucional e, inevitablemente, termina en Derecho comunitario, representa el problema conceptual básico del control ultra-vires. Desde el punto de vista del estándar de revisión «constitucional», si se emplean las gafas del Derecho constitucional nacional, se producirá siempre una caricatura de la distribución de competencias comunitarias. El grado de distorsión de la perspectiva aumenta aún más, cuanto más se aventura el BVerfG en la interpretación de cuestiones competenciales puntuales del Derecho comunitario. En la misma medida aumenta, por lo tanto, el riesgo de una sobrecarga funcional y exceso competencial del BVerfG.

El BVerfG, en su Decisión Honeywell, ha abordado la pregunta sobre cómo, con tales premisas, se puede garantizar con seguridad el monopolio interpretativo del TJUE — iel cual no debería proteger, en último lugar, la igualdad de los ciudadanos a través del Derecho comunitario!—, y lo ha hecho precisando, aún más, el control ultra vires a la luz del fundamento de la amabilidad del Derecho comunitario de la Ley Fundamental ${ }^{72}$. Desde el punto de vista procesal, el BVerfG con-

67 Ibídem, p. 350, Apdo. 234.

68 Ibídem, p. 349, Apdo. 231 y, después, también, p. 382, Apdo. 301.

69 Fundamentalmente TJUE, Sentencia de 5.2.1963 - 26/62 — Van Gend E Loos, Recopilación 1963, pp. 1 y ss. (Apdo. 9 y ss.); TJUE, Sentencia de 15.7.1964 - 6/64 — Costa/ENEL, Recopilación 1964, pp. 1141 y ss. (Apdo. 8 y ss.).

70 De otra manera, BVerfGE 22, 293 (296) — EWG-Verordnungen: «Damit ist eine neue öffentliche Gewalt entstanden, die gegenüber der Staatsgewalt der einzelnen Mitgliedstaaten selbständig und unabbängig ist; (...) das vom EWG-Vertrag geschaffene Recht fließt aus einer, autonomen Rechtsquelle». De otra forma, también en esta línea, BVerfGE 31, 145 (173 s.) - Milchpulver.

71 Compárese también, MAYER, F. «Rebels without a cause?», en GLJ, 2014, p. 111 (117).

72 BVerfGE 126, 286 - Honeywell. Compárese al respecto, SAUER, H., «Europas Richter Hand in Hand?», en EuZW, 2011, p. 94 (95, 97); PAYANDEH, «Constitutional Review of EU Law After Honeywell», en 48 CMLRev. (2011), p. 9 (23 y ss.); Classen, «Anmerkung», en JZ, 2010, 1186 (1186 y ss.); Proelß, 
sidera de forma inequívocamente clara, que al TJUE se le debe dar siempre, ante todo, «la posibilidad de interpretar los Tratados como de decidir sobre la validez y la interpretación de los actos jurídicos inciertos» ${ }^{73}$. Para cumplir con esta condición, se debe igualmente tomar como cierto el mérito clave del auto de remisión del asunto OMC. Desde el punto de vista sustantivo, el BVerfG concreta en el asunto Honeywell, por otra parte, los límites de los elementos probatorios. A partir de entonces, se aplica un doble criterio: el control ultra-vires sólo entrará en juego cuando, en primer lugar, la infracción competencial es manifiesta; y cuando, en segundo lugar, «en el marco competencial existente entre los Estados miembros y la Unión, hay una gran diferencia entre el principio de distribución de competencias y el principio de legalidad», es decir, cuando la actuación comunitaria conlleve un desplazamiento estructural significativo del orden competencial ${ }^{74}$.

cc) La dimensión procesal en el asunto OMC

En el asunto OMC el BVerfG primero amplía, una vez más, el ya señalado marco procesal y, a continuación, declara, por primera vez, la «principal» ${ }^{75}$ alegación de un acto ultra-vires como admisible, además, teniendo como fundamento un fundamento electoral, esto es, basada en el derecho de sufragio. El recurso o cuestión ante Europa con fundamento electoral y la reserva ultra vires se encontraron así por primera vez juntos. Tras las declaraciones del BVerfG en la cuestión presentada por el caso OMC, para la admisibilidad de un recurso de amparo no se ha requerido ninguna alegación más que la vinculación de la actuación ultra-vires con la principal violación de un derecho material (en línea con la constelación dejada por el caso Honeywell, donde fue alegada, principalmente, una lesión de la libertad profesional ${ }^{76}$. Además, tampoco parecía hacer falta ya la alegación de dejar vacío de contenido el derecho de sufragio en su núcleo esencial, es decir, por violación de la cláusula de eternidad garantizada por el artículo 79.3 GG. En estas circunstancias, el riesgo de que se produjera, en general, un aumento del control ultra-vires de los procedimientos de supervisión comunitaria era palpable ${ }^{77}$. Ante

«Zur verfassungsmäßigen Kontrolle der Kompetenzmäßigkeit von Maßnahmen der EU», en EuR, 2011, p. 241 (244 y ss.).

73 BVerfGE 126, 286 (304 y ss.), Apdo. 60-Honeywell.

74 BVerfGE 126, 286 (304 y ss.), Apdo. 61 - Honeywell.

75 Para el concepto, SCHNEIDER, K., «Questions and Answers: Karlsruhe's Referral for a Preliminary Ruling to the Court of Justice of the European Union», en GLJ, 2014, pp. 218 y ss., p. 222.

76 En Honeywell se trataba, en esencia, la supuesta violación de la libertad contractual, constitucionalmente protegida, por una Sentencia del Tribunal Federal de Trabajo que, a su vez, se basaba en la Decisión del caso Mangold del TJUE, que seria clasificada por los reclamantes como un acto ultra-vires.

77 Compárese la opinión divergente del Juez federal, M. Gerhardt a la Sentencia del BVerfG, a la presentación del caso OMC (Nota a pie 12), Apdo. 6. Crítico también, MAYER, F.C., «Rebels Without a Cause?», en GLJ, 2014, pp. 111 y ss., p. 117. 
este panorama, es de agradecer que el BVerfG en su Sentencia final en el caso OMC efectuara varias matizaciones. Aunque, esto no hubiera sido necesario, pues la cuestión presentada al caso OMC no le habría restado claridad. Mientras la presentación del caso OMC provocó la impresión de que este tipo de controles no se vincularían más al marco de un recurso de amparo por un tema electoral si se entendía que el artículo 38.1.1 GG veía garantizado su núcleo esencial a través del artículo 79.3 GG, en la medida en que se alegaría una lesión ultra vires del derecho de sufragio ${ }^{78}$, el BVerfG trabajó desde otro punto de vista en su sentencia definitiva y, de una manera más clara, manifestó que la pretensión de los ciudadanos de defenderse frente a cualificadas violaciones competenciales, debe permanecer bajo el artítuclo 79.3 GG y, por lo tanto, (deben permanecer) limitadas ${ }^{79}$, incluso cuando persistan otras ambigüedades ${ }^{80}$. Además, el Segundo Senado perpetúa y hace operable el criterio, mantenido por primera vez en Honeywell ${ }^{81}$, de la necesidad de evidenciar la lesión de competencias como un factor clave, pero limitado, cuando el mismo reclama que para la admisión de un acto ultra vires, la competencia en cuestión no se haya otorgado mediante la aplicación de un estándar universal fundamentado «desde un punto de vista jurídico» ${ }^{82}$.

\section{dd) Resultado provisional}

El artículo 38.1.1. GG y la, en él anclada, «exigencia de democracia» ${ }^{83}$, tal y como lo ha constatado el BVerfG, «no sirve al control interno del proceso democrático, sino que está destinada a su facilitación» ${ }^{84}$. Pero lo nuevo en el caso OMC y que permanece es lo siguiente: el ciudadano puede dirigirse, pro-

78 Convincentemente, vid. la opinión divergente del Juez federal, M. Gerhardt, a la Sentencia del BVerfG, a la presentación del caso OMC (Nota a pie 12), Apdo. 5.

79 BVerfG, OMC-Decisión Final (Nota a pie 19), Apdos. 126, 147, así como previamente Apdos. 80 y 83 .

80 En otra posición (Apdo. 167) concluyó el BVerfG en el contexto de la integración y de la correspondiente solicitud de los ciudadanos, que los órganos constitucionales alemanes tenían que trabajar por el obvio y estructuralmente importante exceso de competencias anclado en el art. 23.1.3 en conexión con el art. 79.3 GG, en el cumplimiento del proceso de integración, donde los ciudadanos tienen sus derechos.

81 BVerfG, Decisión de 6.7.2010, BVerfGE 126, 286 - (Honeywell). Al respecto SAUEr, H., «Europas Richter Hand in Hand?», en EuZW, 2011, pp. 94 y ss., 95, 97; PAYANDEH, M. «Constitutional Review of EU Law After Honeywell», en CMLRev., 2011, pp. 9 y ss., 23 y ss.; Classen, C.D., »Entscheidungsanmerkung», en JZ 2010, S. 1186 y ss., 1186 y ss.; ProeLß, A., «Zur verfassungsmäßigen Kontrolle der Kompetenzmäßigkeit von Maßnahmen der EU», en EuR, 2011, pp. 241 y ss., 244 y ss.

82 BVerfG, OMC-Sentencia final (Nota a pie 19), Apdo. 149 y ss. y 161 (compárese con BVerfG, OMC-Petición (Nota a pie 12), Apdos. 39, 43). También, entre otros factores limitativos, el BVerfG mantiene el criterio de la estructural transferencia de competencias, compárese Apdo. 151.

83 Así que ahora, literalmente, después de fijar las comillas, pero al mismo tiempo, de forma distanciada, BVerfG, OMC-Sentencia final (Nota al pie 19), Apdo. 185.

84 BVerfG, OMC-Petición (Nota a pie 12), Apdos. 19, 52; BVerfG, OMC-Sentencia final (Nota a pie 19), Apdo. 126. 
tegido por su derecho de sufragio, ante el BVerfG frente a manifiestos excesos competenciales a nivel comunitario. De forma más precisa: el principio democrático, subjetivizado conforme al artículo 38.1.1 GG, prohíbe en su contenido esencial, garantizado a través del artículo 79.3 GG, no sólo una erosión sustancial de la capacidad de decisión del Parlamento alemán por medio de la cesión de los derechos de soberanía, sino que dicho principio también se defiende, de una forma más concreta, a través del principio fundamental de la soberabía popular, frente a los manifiestos estructurales excesos competenciales al nivel comunitario ${ }^{85}$.

\section{c) La crítica}

A pesar de las gratas puntualizaciones realizadas, sin embargo la decisiva sentencia del BVerfG podría no llegar a debilitar las dos principales objeciones realizadas contra la vinculación y trasfondo electoral del control ultra-vires realizada en el caso OMC.

aa) La ausencia de criterios jurídicos

La primera objeción se dirige contra el enfoque dogmático del BVerfG, que estimó sus dos Decisiones sobre el caso OMC, basándose en la inactividad del Parlamento y del Gobierno frente al acto presuntamente ultra-vires manifestado en la forma del Programa OMC. En su Sentencia final, también tuvo éxito el Segundo Senado a pesar de tender nuevos puentes hacia el concepto de las obligaciones de garantía ${ }^{86}$ sin ninguna especificación suficiente, obligaciones que se supone que era lo que exactamente el Parlamento y/o el Gobierno deberían haber cumplido frente al acto realizado ultra-vires por el BCE. El BVerfG no puede aquí, por más tiempo, tanto seguir empleando la frase vacía de contenido, generalmente asumida, de la existencia de un «activo» enfrentamiento entre Tribunales, como proponer unas pocas medidas eficaces, tales como el ejerccio de los derechos de acción, la moción de censura o, incluso, el «euroescéptico fosil ${ }^{87}$ del compromiso con Luxemburgo ${ }^{88}$.

A fin de cuentas, junto al resultado permanece, como constitucionalmente admisible, el analizado argumento de una supuesta inconstitucional inactividad

85 Compárese en especial con la BVerfG, OMC-Decisión final (Nota a pie 19), Apdos. 115, 126, 129 , 132 ss.

86 Finalmente, Apdos. 166 y ss.

87 Preciso, Ruffert, M., VerfBlog de 22.6.2016.

88 BVerfG, OMC-Sentencia final (Nota a pie 19), Apdo. 171. 
del Parlamento y del Gobierno ${ }^{89}$, argumento que no puede mantenerse por mucho más tiempo como el positivo reverso de la responsabilidad de integración asumida a través del compromiso parlamentario de ir «hacia rumbo sorpresa», como en concreto destacó motivadamente la jueza Lübbe-Wolff en su su Voto $\operatorname{particular}^{90}$.

\section{bb) La teórica paradoja democrática}

Una exigencia jurídica de este tipo, de un compromiso parlamentario de este tipo, supone, por otra parte, ir hacia un rumbo incierto en el proceso democrático, al cual hay que pretender proteger. A nivel interno, la crítica perspectiva del juez disidente respecto a la petición presentada en el caso OMC sugiere que el apoyo mayoritario de la Sala al auto de remisión del asunto OMC representó, expresamente, una garantía de la publicidad del procedimiento parlamentario en los casos de graves violaciones de la distribución de competencias $^{91}$. A nivel exterior, la impresión resultante es la de que la jurisprudencia sobre la integración del BVerfG quiere evitar, en último lugar, que puedan ser escuchados todos los puntos de vista, los cuales, debido a la fuerte cultura político-comunitaria del consenso dentro de los grandes partidos políticos en Alemania, pueden permanecer sin ser escuchados ${ }^{92}$. La discusión debería llevar, de nuevo, la responsabilidad del proceso de integración a la publicidad del apoyo decisivo del Parlamento.

El resultado es, sin embargo, algo más que la publicidad en y a través del Parlamento. Más aún, el Tribunal de Karlsruhe se convertirá en un sustituto en la arena política. A este respecto, se puede leer de la jurisprudencia, que representa una «específica y democrática función de válvula o función de compensación» ${ }^{93}$. A

89 BVerfG, OMC-Petición (Nota a pie 12), Apdo. 1, 45 y ss. Conforme al BVerfG, las actuaciones de los órganos de la Unión están dispuestos, en el marco de un control ultra-vires, "para probar su aplicabilidad y vinculatoriedad en Alemania, así como lo están el fundamento de las acciones de los órganos estatales alemanes» (ibídem, Apdo. 23). En el caso del BVerfG, Ayuda financiera a Grecia y FEEF (Nota a pie 31), Apdo. 116, el Tribunal de Karlsruhe había declarado inadmisibles las quejas constituciones en la medida en que se dirigen contra la compra de bonos del Estado en el marco del Programa para los Mercados de Valores (o sus siglas en inglés, SMP-Programms), ya que la compra no representa ningún acto de soberanía de los poderes públicos alemanes y, por lo tanto — con independencia de otras posibilidades de impugnación-, no serían un objeto de queja en el marco de un recurso de inconstitucionalidad. Más detalladamente, Nettesheim, M., «"Euro-Rettung” und Grundgesetz», en EuR, 2011, pp. 765 y ss., 769 y ss.; y Ruffert, M. (Nota a pie 57), p. 847.

90 Opinión discrepante de la Jueza federal G. Lübbe-Wolff a la BVerfG, OMC-Petición (Nota a pie 12), Apdo. 22

91 Ibídem, Apdo. 20.

92 Crítico con el derecho, BAst, J., «Don't Act Beyond Your Powers: The Perils and Pitfalls of the German Constitutional Court's Ultra Vires Review», en GLJ, 2014, pp. 167 y ss., 169.

93 Huber, P.M., en Mangoldt/Klein/Starck (Eds.), GG Kommentar, 6. ${ }^{a}$ Ed. 2010, Art. 19.4 GG, Apdo. 350, en conexión, entre otros, con las Sentencias Lisboa, Maastricht y el caso Euro. 
veces, la acción popular será estilizada al definirse como un «recurso de amparo plebiscitario» con una «función sucedánea de la democracia directa» ${ }^{94}$. Contemplado así, con esta claridad, se presenta el mayor compromiso procesal de buena voluntad del BVerfG en la cuestión de la integración europea, posiblemente como un intento de acercar la integración europea a los ciudadanos.

A este respecto, debería ponerse en duda que un Tribunal constitucional ocupara una posición tanto institucional como estructural. La toma de decisiones dentro del BVerfG tiene lugar a través de un —a su manera, también elitista- órgano colegiado de jueces sobre la base de una aplicación racionalizada de la ley, pero no a través de una decisión mayoritaria de los representantes elegidos o, a caso, de los ciudadanos sobre la base de una opinión pública política en la esfera pública. Además, será ventilada la articulación de intereses de la decisión en las categorías necesarias del Derecho. Los antagonismos políticos (que así se producen) no se presentan, en este punto, como incondicionales, y podrían, de esta forma, en todo caso, no llegar a desarrollarse adecuadamente. Igualmente, es para preguntarse desde una perspectiva jurídica cómo la renuncia consciente de la Ley Fundamental a un elemento plebiscitario puede representar un déficit — que, sobre todo, puede ser reconstruido a través de un recurso jurídico, sin que esto tenga nada que ver, o su correspondencia, con una escala normativa, y que esté más allá de la Constitución en vigor ${ }^{95}$. La teoría democrática lleva implícita la cuestión de en qué medida, en el presunto consenso de los actuales partidos gobernantes sobre las grandes preguntas de política comunitaria, puede encontrarse realmente un déficit democrático, y si éste puede ser solucionado cuando los partidos políticos de otro color fueran representados númericamente en mayor volumen en el Parlamento, para allí (como en numerosos Estados vecinos y cada vez, también, a nivel nacional, se observa) ocuparse de suficientes antagonismos. Es probable, que el BVerfG no quiera ir tan lejos. Pero entonces, a falta de unas medidas jurídicamente más determinantes, la supuesta «falta de acción» del Parlamento y del Gobierno federal debe ser aceptada constitucionalmente como la expresión de la voluntad popular de la mayoría ${ }^{96}$. Esto es aún más válido con vista a las relaciones externas desarrolladas sobre las fronteras de Alemania ${ }^{97}$.

94 KAHL, W. (Nota a pie 56), p. 207.

95 KAHL, W. (Nota a pie 56), p. 207 no se refiere en consecuencia a la Ley Fundamental, sino a la comprobación de que la falta de elementos plebiscitarios demuestra que no se trata ya de «cuestiones básicas de integración fuera de fecha».

96 Gerhardt, M. (Nota a pie 76), Apdo. 23.

97 LÜBBE-WOLFF, G. (Nota a pie 89), Apdo. 28: «Dass einige unabbängige deutsche Ricbter unter Berufung auf die deutsche Auslegung des Demokratieprinzips und auf die Grenzen, die sich bieraus und aus unserer Lesart der Art. 123 ff. AEUV für die zulässigen Befugnisse der unabbängigen Europäischen Zentralbank ergeben, eine Entscheidung mit unkalkulierbar weitreichenden Konsequenzen für die ins Werk gesetzte Wäbrung der gesamten Eurozone und die davon abbängigen Volkswirtschaften treffen, erscheint als Anomalie von böchst zweifelhafter demokratischer Qualität». 


\section{d) Los controles ultra-vires y de identidad: disposiciones proporcionadas}

El BVerfG declaró inadmisible en su pronunciamiento final ${ }^{98}$ la amplia pregunta, formulada ${ }^{99}$ en el auto de remisión en el caso OMC, sobre la violación de la fundamental identidad constitucional en foma de responsabilidad presupuestaria del Parlamento ${ }^{100}$. El BVerfG realiza una aproximación conceptual a los intereses procedimentales generales respecto de los controles de identidad y ultra vires, y a través de su Segundo Senado alude adecuadamente a los excesos manifiestos de competencia al mismo tiempo que a la identidad de la Constitución ${ }^{101}$. Así será estudiada nuevamente la relación, en todo caso, de ambas reservas de control $^{102}$, concibiendo el control ultra vires, desde ahora, como un caso de control de identidad ${ }^{103}$. Este tipo de concepción es acertada para el caso del control ultra-vires con una sustancia electoral, en tanto que, como hemos visto (si se quiere, en general, seguir esta construcción) debe permanecer retroalimentado imperativamente en el artículo 79.3 GG. En otras palabras, en tanto que la alegación ultra-vires con el citado trasfondo electoral sólo es lícita cuando se explica, motivadamente, que el artículo 38.1.1 GG puede verse lesionado, como resultado de un acto manifiesto ultra-vires, en su núcleo intangible garantizado por el artículo 79.3 GG, así los controles ultra-vires y de identidad tienen el mismo punto de partida conceptual: la identidad constitucional. Por supuesto, hay que esperar a ver si la equiparación de un cualificado acto ultra-vires con una lesión de la identidad debería aplicarse también para los supuestos en los que —como en Honeywell- la alegación ultra-vires va unida a la alegación de la violación de un derecho fundamental sustantivo.

Independientemente de esto, existe, sin embargo, una diferencia clave entre un control de identidad y un control ultra-vires. Aunque, en verdad, ambos controles encuentran su fundamento jurídico, en opinión del BVerfG,

98 BVerfG, OMC-Sentencia final (Nota a pie 19), Apdo. 210 y ss.

99 BVerfG, OMC-Petición (Nota a pie 12), Apdo. 102 y ss. En concreto, esta restricción se refería, en parte, primero, al programa de la OMC, en su totalidad, sobre la base de la interpretación dada por el TJUE y, por otra parte, en segundo lugar, sobre la base de medidas de trasposicion en el futuro.

100 Conforme al caso del BVerfG, Ayuda financiera a Grecia y FEEF (Nota a pie 31), Apdo. 121 y ss., así como el caso del BVerfG, MEDE y Pacto Fiscal - Decisión rápida (Nota a pie 26), Apdo. 107 y ss., el núcleo esencial del principio democrático, como parte de la identidad constitucional protegida por el art. 79.3 GG, se vería lesionado cuando la responsabilidad presupuestaria del Parlamento se viera comprometida, expresamente cuando a través de obligaciones comunitarias o internacionales un mecanismos tuviera que basarse en la «Asunción de la responsabilidad por las decisiones voluntarias de otros Estados» y conforme a lo cual ya no podría ejercer su propia responsabilidad financiera sobre sus derechos presupuestarios.

101 Ibídem, Apdo. 153.

102 Cercano a la relación de los controles de identidad y ultra-vires, Wendel, M., (Nota a pie 5), pp. 474 y ss., así como MAYer, F.C. / Wendel, M., EnzEuR I, 2014, § 4 Apdo. 249 y ss. Compárese, también, Schwerdtfeger, A., «Europäisches Unionsrecht in der Rechtsprechung des Bundesverfassungsgerichts», en EuR, 2015, pp. 290 y ss., 294 y ss.

103 BVerfG, OMC-Sentencia final (Nota a pie 19), Apdo. 153. 
en el «fundamento constitucional del poder de la Unión» ${ }^{104}$. A ojos del BVerfG el Derecho comunitario, a pesar de sus postulados de autonomía normativos, no es mucho más que un derivado de la regulación estatal ${ }^{105}$. Mientras, el concepto de la identidad constitucional sirve sólo, desde el punto de vista del Derecho constitucional alemán, para manifestarse sobre la capacidad competencial de los actos comunitarios, y generalmente, lo podemos encontrar, en primer lugar, a través de la interpretación de los Tratados. Por otro lado, el control ultra-vires dirigido sobre el cumplimiento del — por la Ley de ratificación- consentido programa de integración no puede limitarse a la prueba de la adecuación sólo desde el punto de vista de la Ley Fundamental, sino que debe enfrentarse al monopolio interpretativo del TJUE, en tanto que más allá de una prueba del Derecho comunitario derivado, es, al mismo tiempo, una prueba a la vista del Derecho originario. Este híbrido, porque comienza estándares de revisión en Derecho constitucional e, inevitablemente, los termina en el Derecho comunitario, diferencia el control ultra-vires fundamentalmente del control de identidad. Un Tribunal nacional que reconoce un acto ultra-vires, en verdad, confirma sólo formalmente $-\mathrm{y}$, ciertamente en contra del monopolio interpretativo del TJUE y del principio comunitario de primacía- la inaplicabilidad estatal interna de este acto, pero en esencia está alegando nada menos que su ilegalidad comunitaria. La reserva de identidad, frente al control ultra-vires, comparte esta diferencia, por lo demás, con la reserva de los derechos fundamentales manifestada en la jurisprudencia seguida en Solange ${ }^{106}$.

La relación entre Solange y la reserva de identidad no habría debido influir en la Decisión final en el caso OMC. Y, sin embargo, existe una confirmación indirecta de la misma a través de los numerosos obiter dicta que, debido a la Decisión del caso Haftbefehl II, de 15 de diciembre de 2015 — con la que el BVerfG ha reconocido que la reserva de identidad está basada únicamente en el ámbito de aplicación de la dignidad humana frente a la fomulación abstracta y general de su

104 BVerfG, Tratado de Lisboa (Nota a pie 54), Apdo. 234.

105 Entre otras, BVerfGE 22, 293 (296) - (Reglamentos de la CEE): «Damit ist eine neue öffentliche Gewalt entstanden, die gegenüber der Staatsgewalt der einzelnen Mitgliedstaaten selbständig und unabhängig ist; (...) das vom EWG-Vertrag geschaffene Recht fließt aus einer, autonomen Rechtsquelle». Otras, en la misma línea, también, BVerfGE 31, 145 (173 y ss.) — (Milchpulver).

106 Véase así, MAYER, F.C., Kompetenzüberschreitung und Letztentscheidung, 2000, p. 108, el cual, consideró innecesaria la propuesta presentada ante el TJUE, tras la concepción del Tribunal de Karlsruhe en el caso del control de identidad por una lesión del art. 4.2.1 TUE. Esta declaración provoca una determinada y posible forma de comprender la identidad por parte del BVerfG. Mientras que en la Sentencia Lisboa se había puesto el acento en los conceptos internos de la defensa de la identidad constitucional y comunitaria, ambas iban «mano a mano», en el caso de la presentación del caso OMC, se centró en la identidad constitucional alemana en el sentido del art. 79.3 GG, conceptualmente diferenciada de la identidad nacional en el sentido del art. 4.2.1 TUE. Finalmente, no sólo se dibujaría materialmente —incluso sería indiferente_, sino que podría, cocretamente por la capacidad de ponderación del art. 79.3 GG, no garantizarse conceptualmente el núcleo de la identidad alemana. Se clasifica así, en sentido amplio, la reserva de los derechos fundamentales como un acto ultravires. 
primacía en el caso Solange ${ }^{107}$ _ , en el futuro se tratarán en Karlsruhe sobre la identificación de un integración más sólida del núcleo de la dignididad humana ${ }^{108}$.

En general, el control de identidad avanza cada vez más hacia la esencia de un fundamental «derecho de defensa» en el tema de la integración europea. Así, la citada jurisprudencia sobre la esencial garantía constitucional sobre la inmunización se encontró un considerable conflicto potencial, no sólo desde la perspectiva comunitaria. Mejor dicho, a través de una consideración constitucional, se encontró también una amenaza, un proceso de «desdiferenciación de la distinción entre el Derecho constitucional resistente al cambio» ${ }^{109}$, o un pretórico proceso de «endurecimiento y despolitización», en el que los límites para justificar entre lo político y lo incondicional se desdibujan cada vez más frente a una revisión constitucional rígida para la protección de los bienes esenciales ${ }^{110}$.

\section{e) Ordenamiento jurídico comparado}

El BVerfG intenta, no por último, apoyar su argumentación también explícitamente a través de consideraciones constitucionales comparadas. De este modo se excede el marco de referencia de la Constitución y se refleja un fenómeno paneuropeo, con medios de argumentación de Derecho comparado, en forma de un diálogo guiado entre los Tribunales Constitucionales nacionales ${ }^{111}$. Esto, a su vez, está nuevamente incluído en el marco más amplio de la apertura horizontal del ámbito nacional y de la formación del Derecho constitucional común europeo ${ }^{112}$ o, respectivamente, de un «nuevo» ius publicum euro$p e o^{113}$. Con vistas a la argumentación basada en el Derecho constitucional comparado, sin duda, la identificación de unos estándares comunes se puede entender, también, por supuesto, como una manifestación de la solidaridad colectiva frente al TJUE. El recurso a las principales decisiones de otros Tribu-

107 BVerfG, Decisión de 15.12.2015.

108 BVerfG, OMC-Sentencia final (Nota a pie 19), Apdo. 138 («Wahrung des Menschenwürdekerns der Grundrechte»). Sobre este problema, Reinbacher, T. / Wendel, M., «Menschenwürde und Europäischer Haftbefehl», en $E u G R Z, 2016$, en detalle.

109 Schönberger, C. «Anmerkung», en JZ, 2016, p. 422 (424), en relación a la Decisión en el caso Haftbefehl-II.

110 Véase, NetTesheim, M., «Anmerkung», en JZ, 2016, 424 (428), también en relación con la Decisión Haftbefebl-II.

111 En detalle, Wendel, M., «Richterliche Rechtsvergleichung als Dialogform», en Der Staat, 52/2013, p. 339 ss.; Boвeк, M., Comparative Reasoning in European Supreme Courts, 2013, pp. 237 y ss.

112 Häberle, P., «Gemeineuropäisches Verfassungsrecht», en $E u G R Z, 1991$, pp. 261 y ss.; del mismo, "Gemeineuropäisches Verfassungsrecht», en BIEBER/WIDMER (Ed.), L'espace constitutionnel européen, 1995, pp. 361 y ss.; HeInTZEN, M., «Gemeineuropäisches Verfassungsrecht in der Europäischen Union», en EuR, 1997 , pp. 1 y ss., 15.

113 En detalle, Bogdandy, A. Von / Hinghofer-Szalkay, S., «Das etwas unheimliche Ius Publicum Europaeum», en Zä̈RV, 73/2013, pp. 209 y ss., 212 y ss. 
nales constitucionales sirve, por lo tanto, como un respaldo argumentativo en contra del Tribunal de Justicia. En este sentido se entienden las declaraciones comparadas del BVerfG en el auto de remisión en el asunto OMC y en el fallo final del mismo caso. En ambas decisiones, el BVerfG explica, bajo la referencia a toda una serie de Decisiones sobre integración de otros Estados miembros incluida la referencia al Tribunal Constitucional español-, que los recapitulados principios fundamentales por él para la defensa de los límites de la cesión de soberanía y de la identidad constitucional nacional se encontraban también en el Derecho constitucional de otros muchos Estados Miembros de la UE ${ }^{114}$.

aa) Las vías de recepción del control ultra-vires

Es cierto que el concepto de la reserva ultra-vires elaborado por la jurisprudencia constitucional federal ha sido recibido por una gran mayoría de Estados a nivel comunitario en diversas ocasiones ${ }^{115}$. En el pasado, han hecho suyo el planteamiento: el Alto Tribunal danés ${ }^{116}$, el Tribunal Constitucional polaco $^{117}$, así como el Tribunal Constitucional checo (VerfG) ${ }^{118}$. Planteamientos parecidos son identificados, además, entre otros, en el Derecho constitucional húngaro y en el de Estonia ${ }^{119}$. Estos enfoques varían considerablemente a la hora de su respectiva configuración. De hecho, hasta ahora, ha venido siendo practicado un control ultra-vires parecido al del BVerfG únicamente por el Tribunal Constitucional (TC) checo $^{120}$, en un caso en el que, a causa de un conflicto de competencias entre el Tribunal Constitucional y el Tribunal Supremo Administrativo, el Derecho comunitario no era tanto la causa, sino más bien un medio de disputa ${ }^{121}$.

114 BVerfG, OMC-Petición (Nota a pie 12), Apdo. 30; BVerfG, OMC-Sentencia final (Nota a pie 19), Apdo. 142.

115 Detenidamente sobre el problema, con una perspectiva comparada, MAYER, F.C., Kompetenzïberschreitung und Letztentscheidung, 2000, pp. 87 y ss.; WendeL, M. (Nota a pie 5), pp. 462 y ss.

116 Tribunal Supremo danés, Sentencia de 6.4.1998, I 361/1997 (Carlsen/Rasmussen), EuGRZ 1999, 49, 52 en su traducción al alemán. Este enfoque, sin embargo, no se recogió en Decisiones más recientes de forma similar. Véase, especialmente, la Sentencia de 20.2.2013, 199/2012 (Tratado de Lisboa) y la jurisprudencia de Krunke, H., en EuConst, 2014, pp. 542 y ss.

117 Tribunal Constitucional polacao, Sentencia de 11.5.2005, K 18/04 (Tratado de Adhesión), EuR 2006, pp. 236 y ss., 238 y ss. y 243.

118 Tribunal Constitucional checo, Sentencia de 26.11.2008, Pl. ÚS 19/08 (Tratado de Lisboa I), Apdos. 120, 139 y 216.

119 Esto no puede ser analizado en detalle aquí. Más próximo, Wendel, M. (Nota a pie 5), pp. 468 y ss.

120 Tribunal constitucional checo, Sentencia de 31.1.2012, Pl. ÚS 5/12 (Pensiones eslovacas), Sección VII. Al repecto, KoмÁreK, J., «Czech Constitutional Court Playing With Matches», en EuConst, 8/2012, pp. 323 y ss.

121 En última instancia, se ha establecido la disputa por otros motivos. Por todos, BoBeK, M., «Landtová, Holubec, and the Problem of an Uncooperative Court», en EuConst 10/2014, pp. 54 y ss. 
bb) Control de identidad preventivo y defensivo

Con vistas al control de identidad hay que tener en cuenta, además, que la diferencia en los enfoques de los Tribunales constitucionales nacionales se basa no sólo en la «existencia o inexistencia del inalterable contenido de las respectivas Constituciones nacionales», como el BVerfG sugiere ${ }^{122}$. Si bien, es cierto que existen importantes prohibiciones de revisión (y, por lo tanto, potenciales cláusulas de eternidad) en numerosas Constituciones europeas ${ }^{123}$. La cuestión esencial, sin embargo, no es si una Constitución contiene una cáusula de eternidad, sino si y en qué medida ésta se deja llevar a la práctica en el contexto de la integración europea por parte de un Tribunal Constitucional — ya sea contra el poder de reforma constitucional, ya sea contra el poder de la Unión-. En este sentido, si se quiere establecer el control de identidad que realiza el BVerfG en un contexto de Derecho comparado, se debe tener en cuenta, por lo tanto, la justiciabilidad de una cláusula de este tipo. Desde este punto de vista, el control de identidad del BVerfG en el Derecho comparado es un modelo único. Este control es válido tanto desde un punto de vista defensivo - analizando si un acto jurídico comunitario válido que contraviene el artículo 79.3 GG en Alemania debe permanecer inaplicable o no debe servir como fundamento de las acciones de los poderes púbicos alemanes-, como también desde un punto de vista preventivo, donde se realiza de antemano este tipo de control frente a la modificación de un Tratado o la entrada de cualesquiera obligaciones internacionales.

Si bien es cierto que numerosos Tribunales constitucionales en sus decisiones sobre integración recurren al concepto de la identidad (constitucional) ${ }^{124}$, también es cierto que ningún otro Tribunal constitucional ha hecho operable una prohibición de revisión constitucional en el contexto de la integración europea comparable y explicada normativamente como lo ha hecho el BVerfG. Sólo Karlsruhe ha deducido de una cláusula, que sirve en primera línea a la finalidad de prevenir una recaída en la Dictadura ${ }^{125}$, una detallada lista de ámbitos sensibles a la identidad nacional y los ha enfrentado a la posición de la integración

122 Así, BVerfG, OMC-Petición (Nota a pie 12), Apdo. 30. En general - y de forma muy relevantea continuación, BVerfG, OMC-Sentencia final (Nota a pie 19), Apdo. 142.

123 Una visión comparada de las prohibiciones de revisión, en WENDEL, M., (Nota a pie 5), pp. 331 y ss.

124 Consejo de Estado francés, Decisión de 19.11.2004, 2004-505 DC (Tratado constitucional), Apdo. 13 y Decisión de 27.7.2006, 2006-540 DC (Sociedad de la información), Apdo. 19; Tribunal constitucional español, Decisión de 13.12.2004, n. ${ }^{\circ} 1 / 2004$ (Tratado constitucional), EuR 2005, pp. 339 y ss., 343 y ss., 355; Tribunal Constitucional checo, Tratado de Lisboa-I (Nota a pie 117), Apdo. 120 y Sentencia de 3.11.2009, Pl. ÚS 29/09 (Tratado de Lisboa II), Apdo. 150; Tribunal Constitucional de Lituania, Sentencia de 7.4.2009, 2008-35-01 (Tratado de Lisboa), Sección 16.3; Tribunal Constitucional húngaro, Sentencia de 12.7.2010, 143/2010 (Tratado de Lisboa), Sección III.1; Tribunal constitucional polaco, Sentencia de 24.11.2010, K 32/09 (Tratado de Lisboa), Parte III.2.1, III.3.8.

125 Véase al respecto el Voto particular de la Jueza federal G. Lübbe-Wolff a la BVerfG, Sentencia de 18.7.2005, BVerfGE 113, 273 — (Orden de detención europea), Apdo. 178. 
europea $^{126}$. En otros ordenamientos constitucionales europeos las importantes prohibiciones de revisión se llevan a cabo, a menudo, por la judicatura con la máxima reserva. Así lo explicó el Tribunal Constitucional checo en su segunda sentencia sobre el caso Lisboa manteniendo que, con vista a la separación horizontal de poderes, no debió permitirse la competencia y debería haberse hecho operable la (normativa y estructuralmente comparable con el artículo 79.3 GG) prohibición de revisión de la Constitución checa de una forma parecida a como lo hace el BVerfG ${ }^{127}$. Un clásico ejemplo del restrictivo manejo de la prohibición de revisión la ofrece, además, la jurisprudencia del Consejo Constitucional francés con el artículo 89.5 de la Constitución francesa. La cuestion previa de si esta norma - la cual venía a prohibir la monarquía como forma de gobierno en Francia_- ${ }^{128}$, puede ser entendida, sobre todo, como una medida de una supra-constitutionnalité (supraconstitucionalidad), es en la literatura jurídica un tema muy controvertido $^{129}$. Junto a la doctrina, pero entre todos, también el Consejo constitucional, hacen prevalecer ${ }^{130}$ una gran cautela, y hasta hoy, no se han deducido del artículo 89.5 de la Constitución ningunos límites de reforma para la adhesión de Francia a la UE. Por el contario, el Consejo constitucional, a través de un amplio conjunto de normas constitucional ha deducido como una barrera a la integración, «los requisitos básicos para el ejercicio de la soberanía nacional», marcándolos sólo como el umbral necesario para poder llevar a cabo una reforma constitucional ${ }^{131}$. También, en cuanto el Consejo constitucional recurre expresamente al concepto de identidad constitucional, se entiende que existe no sólo la resistencia al cambio, sino que permanece la posibilidad de una reforma constitucional ${ }^{132}$. En este

126 Conforme al caso del BVerfG, Tratado de Lisboa (Nota a pie 54), Apdo. 249, la integración europea «no debería materializarse en el sentido de que en los Estados miembros no permaneciera ningún espacio suficiente para su política económica, cultura y social». En este sentido, integra el Tribunal «la ciudadanía, el monopolio del poder civil y militar, los ingresos y los gastos de los préstamos, así como las medidas de intervención para la realización de los derechos fundamentales, ante todo por medio de la intensiva intromisión en los derechos fundamentales como la detención en los casos de justicia penal, o por medidas de internamiento", así como «también cuestiones culturales como la disposición de la lengua, la organización de las condiciones de la familia y la educación, la regulación de las libertades de pensamiento, prensa y reunión, o lo relativo a las creencias religiosas o ideológicas». De forma concisa, la crítica de ScHöNBERGER, C., «Die Europäische Union zwischen "Demokratiedefizit" und Bundesstaatsverbot», en Der Staat, 48/2009, pp. 535 y ss., 553 y ss.

127 Tribunal constitucional checo, Trtado de Lisboa II (Nota a pie 123), Apdos. 110-113.

128 Así, ya, art. 8.2 Constitución francesa de la III República, desde la reforma constitucional de 1884.

129 Para la problemática en detalle, Ziller, J., «Sovereignty in France: Getting Rid of the Mal de Bodin», en Walker (Ed.), Sovereignty in Transition, 2003, pp. 261 y ss., 271 y ss., con numerosas referencias.

130 Consejo constitucional francés, Decisión de 26.3.2003, 2003-469 DC (Descentralización), Apdo. 2.

131 Consejo constitucional francés, Decisión de 9.4.1992, 92-308 DC (Tratado de Maastricht I); Decisión de 31.12.1997, 97-394 DC (Tratado de Amsterdam); Decisión de 19.11.2004, 2004-505 DC — Tratado constitucional; Decisión de 20.12.2007, 2007-560 DC (Tratado de Lisboa).

132 El Consejo constitucional sustuvo la identidad constitucional (que en Francia tiene sus raíces en el Derecho Constitucional) de la obligación para implementar una Directiva, pero se refirió expresamente a la posibilidad de una reforma constitucional. Véase, la Decisión de 27.7.2006, 2006-540 DC (Sociedad de la información), Apdo. 19, así como al respecto Chaltiel, F., «Nouvelle précision sur les rapports entre le droit constitutionnel et le droit communautaire», en RFDC, 78/2006, pp. 837 y ss. 
sentido, las concepciones de la identidad constitucional francesa y alemana se diferencian fundamentalmente ${ }^{133}$.

Desde luego habría que considerar si el catálogo de identidad formulado en la sentencia alemana sobre el caso Lisboa debería cumplir unicamente una función de advertencia para las futuras cesiones de soberanía ${ }^{134}$, si se pensó, además, con anterioridad, en un escenario amenazante para el proceso político, o en un borroso horizonte de referencia para el futuro control de identidad preventivo. Que la Directora Lagarde del FMI abandonara la Sala cuando se pronunciaban las palabras «Tribunal Constitucional Federal» ${ }^{135}$, muestra, al menos indirectamente, el significado del ex ante o preventivo límite de identidad en el proceso político. Los ámbitos asignados al catálogo de identidad fueron descritos por el BVerfG en la Sentencia Lisboa como aquellos ámbitos «especialmente sensibles para la capacidad de autocreación democrática» ${ }^{136}$. Esto se puede entender, tras una lectura moderada, en el sentido de que una cesión de competencias dentro de este ámbito contiene, sólo desde una perspectiva ex ante, el peligro de una violación de la identidad. De acuerdo con esta interpretación, el BVerfG habría delimitado en la Sentencia Lisboa, «solamente» una zona material de riesgo. Entonces, habría que diferenciar y delimitar la esencial y absoluta «estrecha zona de exclusión», dentro de la cual se garantizan principios esenciales conforme al artículo 79.3 GG, de los casos individuales que se podrían ver lesionados. En el marco de un control de identidad defensivo, nos encontraríamos ante un ámbito estrechamente delimitado y sólo recurriríamos al mismo cuando nos encontráramos una concreta violacion del artículo 79.3 GG a través de un determinado acto jurídico de la Unión. Pero incluso en el supuesto de que se imputara al BVerfG el ser tan cauteloso en el marco de un control defensivo como en el de uno preventivo, conforme al artículo 79.3 GG, queda, en todo caso, en manos de la especialidad del Derecho comunitario, el hecho de que un Tribunal Constitucional haga operativa una cláusula de eternidad para la (potencial) inaplicabilidad por parte del Estado del Derecho comunitario.

\section{EL MARCO PROCESAL DEL TJUE: LA JUDICIAL DISTRIBUCIÓN DE TAREAS EN UN SISTEMA MULTINIVEL}

En cuanto a la relación dialógica del BVerfG y el TJUE, el Tribunal de Justicia interpreta en el caso Gauweiler y otros las disposiciones pertinentes del

133 En particular, Walter, M., «Integrationsgrenze Verfassungsidentität», en Zä̈RV, 72/2012, pp. 177 y ss., 179 y ss.; Reestman, J.-H., «The Franco-German Constitutional Divide», en EuConst, 2009, pp. 374 y ss.

134 Véase, la aceptación de compromisos internacionales.

135 Véase, sólo el Frankfurter Allgemeine Zeitung (FAZ) de 7.7.2012. Disponible en http://www.faz. net/aktuell/wirtschaft/bundesverfassungsgericht-europa-haengt-an-einer-unterschrift-11813446.html.

136 BVerfG, Tratado de Lisboa (Nota a pie 54), Apdo. 252. 
Derecho primario, como era de esperar, en el sentido de que las mismas permiten la elaboración de un Programa, como el del caso OMC, por parte del BCE, y lo hace indicando junto al margen de apreciación del BCE, los límites legales de la UEM (Unión Económica y Monetaria) ${ }^{137}$. Al mismo tiempo, el TJUE se planteó las cuestiones de admisibilidad alegadas en la cuestión prejudicial presentada, y no en último lugar, en el procedimiento principal con causa del control ultra vires. De manera similar a como ya se había hecho en el caso Pringle ${ }^{138}$, el Tribunal de Justicia fue al encuentro del presente BVerfG, pero a través de técnicas de cooperación combinada en forma de reconocimiento de unas prerrogativas procesales de estimación o evaluación, especialmente con vistas a la evaluación de la pertinencia de la cuestión prejudicial para el procedimiento principal.

\section{Las prerrogativas de evaluación como técnica combinada}

En realidad, cualquier espectador habría esperado, al menos, que el TJUE desestimara la cuestión prejudicial del BVerfG por improcedente. No obstante, el despliegue argumentativo ofrecido fue considerable. Numerosos Estados miembros y órganos de la UE habían formulado en procedimientos ante el TJUE sustanciales objeciones frente a la admisibilidad. La duda comenzó con la pregunta de si podía ser estimada la pretensión sólo teniendo conocimiento del acto a través de un comunicado de prensa, esto es, frente a una Decisión publicada en prensa, pero hasta entonces, no controvertida ni manifestada oficialmente, si esto era un objeto admisible para la validez de la pretensión (artículo 267.b) TFUE) ${ }^{139}$. Mientras el Abogado General, Cruz Villalón, contestó a esta pregunta con unos argumentos convincentes en sentido positivo ${ }^{140}$, el TJUE la dejó finalmente abierta bajo la advertencia de que el BVerfG, en todo caso, había preguntado también por la interpretación de las normas pertinentes de los Tratados, conforme al artículo 267.a) TFUE ${ }^{141}$. Así las cosas, el TJUE dio una respuesta al asunto sólo sobre el problema de la interpretación del acto (presentado por parte del BVerfG con carácter subsidiario), dejando, sin embargo, sin explicar la cuestión de la validez para la admisibilidad ${ }^{142}$.

Igualmente, la decisión sobre la pertinencia de las cuestiones prejudiciales presentadas tropieza, de antemano, con serias preocupaciones sobre el control ultra-vires.

137 TJUE, C-62/14 (Ganweiler y otros), EU:C:2015:400.

138 TJUE, C-370/12 (Pringle), EU:C:2012:756, Apdo. 30 y ss.

139 Con base en el TJUE, C-322/88 (Grimaldi), EU:C:1989:646, Apdo. 8 había estado bien justificado, ya que el TJUE conforme al art. 267 TFUE confiere el poder «im Wege der Vorabentscheidung über die Gültigkeit und die Auslegung der Handlungen der Organe der Gemeinschaft obne jede Ausnabme zu entscheiden».

140 Abogado General, Cruz Villalón, Conclusiones generales, de 14.1.2015, C-62/14 (Gauweiler y otros), EU:C:2015:7, Apdos. 71-90.

141 TJUE, C-62/14 (Gauweiler y otros), EU:C:2015:400, Apdo. 30 en comparación con Apdo. 23.

142 Ibídem. 
Las cuestiones procesales constitucionales que se producen a nivel nacional encuentran, aquí también, su repercusión comunitaria: ¿Existe la posibilidad, manifestada abiertamente por el BVerfG, de no verse vinculado, en casos extremos, a la jurisprudencia del TJUE sobre unas cuestiones prejudiciales no planteadas hipotéticamente o sobre un dictamen inadmisible? ¿El litigio principal se convierte, debido a sus especialidades, en un litigio ficticio o, incluso, reconstruido? En contra de la opinión jurídica de numerosos Estados miembros y órganos comunitarios, el TJUE decidió, con bastantes buenas razones, que esto no era asi ${ }^{143}$, que además, la presunción de la decisión de la pertinencia, cuestión ya analizada ${ }^{144}$ en detalle en el pasado, había tenido lugar también en el presente caso a favor del BVerfG ${ }^{145}$.

El reducido nivel de control practicado en relación con la decisión de la pertinencia de la cuestión planteada no responde a otra cosa sino a la función de una técnica combinada en un contexto plural de ordenamientos jurídicos ${ }^{146}$. El TJUE reconoce a los Tribunales nacionales, especialmente a los Tribunales Constitucionales, una prerrogativa procesal de estimacion bastante amplia con vistas a la posterior pertinencia de la cuestión prejudicial. Al mismo tiempo, el Tribunal de Justicia parte, acertadamente, de «una clara separación de funciones entre los Tribunales nacionales y el Tribunal de Justicia», en virtud de la cual, «cada valoración de los hechos cae dentro de la competencia de los Tribunales nacionales, que deben valorar, a la vista de las especialidades de los asuntos, tanto la necesidad de una decisión prejudicial para la promulgación de su sentencia, así como también la pertinencia de las preguntas presentadas ante el Tribunal de Justicia (...), mientras que el Tribunal de Justicia sólo está facultado para manifestarse sobre el fundamento de los hechos que le presentan los Tribunales nacionales pero en relación con la interpretación o validez de la normativa comunitaria» ${ }^{147}$. En otras palabras, el Tribunal de Justicia renuncia dentro del marco del Derecho comunitario a cualquier tipo de control cooperativo. En este punto nos encontramos directamente con un paradigmático ejemplo de aplicación de un pluralismo constitucional cooperativo ${ }^{148}$.

143 TJUE, C-62/14 (Gauweiler y otros), EU:C:2015:400, Apdo. 24 y ss.

144 Ejemplar, TJUE, C-144/04 (Mangold), EU:C:2005:709, Apdo. 34 y ss. Especialmente para la relación con los Tribunales constitucionales nacionales, TJUE, C-399/11 (Melloni), EU:C:2013:107, Apdo. 28 y ss.

145 Esto presupone que falta, evidentemente, un punto de conexión entre la interpretación solicitada y la finalidad del procedimiento principal; que el problema jurídico es de naturaleza hipotética; o que al TJUE le faltan los requisitos materiales para una respuesta material o información jurídica. Véase, TJUE, C-244/80 (Foglia/Novello II), EU:C:1981:302, Apdo. 16-21, así como en resumen TJUE, C-467/05 (Dell'Orto), EU:C:2007:395, Apdo. 40; y C-379/98 (PreussenElektra), EU:C:2001:160, Apdo. 38 y ss. Como ejemplo de un caso, véase TJUE, C-83/91 (Meilicke), EU:C:1992:332, Apdo. 30 y ss. En particular, KarpensteIN, U., en Grabitz / Hilf / Nettesheim (Eds.), Das Recht der Europäischen Union, Art. 267 TFUE, 50. EL 2013, Apdo. 25 y ss.

146 Para el concepto de la técnica combinada sobre el fundamento del pluralismo constitucional, WENDEL, M., (Nota a pie 5), pp. 33 y ss., con más referencias.

147 TJUE, C-62/14 (Gauweiler y otros), EU:C:2015:400, Apdo. 15.

148 Para un cooperativo pluralismo constitucional, MAYER, F.C., (Nota a pie 5), pp. 38 y ss. Para un pluralismo dialógico, véase BOGDANDY, A. vON, «Prinzipien von Staat, supranationalen und internationalen Organisationen», en $H S t R, \mathrm{XI}, 3 .^{\mathrm{a}}$ Ed., 2013, § 232, Apdo. 55. 
A un nivel todavía más fundamental, hay que señalar, sin duda, que la aplicación de un control ultra-vires en contra del artículo 19.1.2 TUE y del artículo 344 TFUE viola y menoscaba la finalidad esencial de la garantía de la unidad, a la cual deberían ir destinados a satisfacer tanto el procedimiento prejudicial como el monopolio interpretativo del Tribunal de Justicia en el Derecho comunitario ${ }^{149}$. Que el BVerfG en el caso OMC tomara en «consideración» la especial función del Tribunal de Justicia en el ámbito de los procedimientos prejudiciales, como reclama la actual jurisprudencia del TJUE ${ }^{150}$, debe ser puesto en duda. La cuestión planteada indicaba abiertamente no sólo los límites de la voluntad de cumplimiento del BVerfG — de hecho la declara como un caso excepcional. El BVerfG remitió también al TJUE la interpretación constitucional federal del pertinente Derecho comunitario al estilo de los seguidores de una reclamación ${ }^{151}$. Por este motivo, el TJUE debió evitar que a través de la recepción de la propuesta surgiera la impresión de una implícita aprobación comunitaria de las reservas de control efectuadas por el Tribunal de Karlsruhe. Sin embargo, el TJUE no permitió provocar ninguna duda, sino que determinó en sus concisas observaciones preliminares, que «una sentencia del Tribunal de Justicia sobre un procedimiento prejudicial vincula, de acuerdo con jurisprudencia reiterada, al Tribunal nacional respecto a la interpretacion o a la validez de los actos cuestionados de los órganos comunitarios para la decisión sobre el procedimiento principal» ${ }^{152}$. Esta mera aclaración en la materia, en su brevedad pero al mismo tiempo en su totalidad es bienvenida calurosamente. El TJUE sigue, en este sentido, la vía diplomática del Abogado General, el cual en sus Conclusiones planteó con cautela, el «problema funcional» del control ultra-vires, manifestando que aún siendo ejecutado con desigual detalle y con vistas al principio de cooperación leal, el Tribunal de Justicia debería «dentro de los límites de lo razonable confiar al respecto» en que el BVerfG «considerará la respuesta recibida como suficiente y definitiva» ${ }^{153}$.

\section{La respuesta del BVerfG: los márgenes de una concreción legal}

A pesar de que el BVerfG no acogió abiertamente la crítica articulada en la argumentación del Tribunal de Justicia ${ }^{154}$, finalmente aceptó la decisión del TJUE.

149 De la primera jurisprudencia, especialmente, TJUE, C-188/10 y C-189/10 (Melki y otros), Apdo. 54 en relación con la francesa «question prioritaire de constitutionnalité»(QPC).

150 TJUE, C-244/80 (Foglia/Novello II), EU:C:1981:302, Apdo. 20.

151 La presentación se comparará, no injustamente, con un dictado. Véase, MAYER, F.C., (Nota a pie 76), p. 119; Pliakos, A. / Anagnostaras, G., «Blind Date Between Familiar Strangers», en GLJ, 2014, pp. 369, 376.

152 TJUE, C-62/14 (Ganweiler y otros), EU:C:2015:400, Apdo. 16.

153 Abogado General, Cruz Villalón, Conclusiones generales, de 14.1.2015, C-62/14 (Gauweiler y otros), EU:C:2015:7, Apdo. 67.

154 BVerfG, asunto OMC (Nota a pie 19), Apdo. 181 y ss. 
En este caso, jugó un papel decisivo el reconocimiento de los diferentes niveles de los márgenes de apreciación: dogmáticamente el BVerfG confiesa al TJUE, ante el criterio de la evidencia, un margen de concreción legal autónomo, el cual encuentra sus límites, primero en una «decididamente no más comprensible, y, posteriormente, en una objetivamente arbitraria interpretación de los Tratados» ${ }^{155}$. En relación con esta cuestión, encontramos el reconocimiento del ya mencionado, en el caso Honeywell, método pluralista, que busca un balance entre la autonomía y la vinculación a las tradiciones de los Estados miembros, teniendo en cuenta la exigencia del TJUE de una «tolerancia de fallos» ${ }^{156}$. La adjudicación de los márgenes como una técnica combinada funciona, por lo tanto, en ambas direcciones.

\section{EL NIVEL DE CONTROL Y LOS CRITERIOS DE CONTROL}

El acercamiento constitucional a las medidas contra la crisis comunitaria e internacional se evidencia como algo difícil no sólo por su continua transformación sino por su desarrollo expansivo. Pero desde una perspectiva jurídica los desafíos son, ante todo, la construcción de unos estándares constitucionales, así como la gestión de pronósticas y empíricas incertidumbres ${ }^{157}$.

\section{El Nivel de control jurídico del BVerfG y del TJUE en comparación}

El último citado aspecto recuerda ya a una pregunta fundamental para el acercamiento jurídico a la crisis económica y financiera: ¿en qué medida se podrían formular categorías de Derecho constitucional europeo o nacional, aplicables sobre todo ante los Tribunales, sin extender en exceso los límites normativos o funcionales de los mandatos legales existentes? Esta cuestión está directamente vinculada con la pregunta del nivel de control jurídico. El Derecho comparado evidencia que la diferencia del nivel o grado de control en el tratamiento judicial no sólo va a depender del nivel jurisdiccional, sino, en especial medida también, de la institución a la que esté sujeta la función de control.

\section{a) La prerrogativa de estimación del Parlamento frente a las medidas de rescate extra} comunitarias

Si el principio democrático desde un punto de vista jurídicamente material, se encuentra en el centro de la crisis constitucional del Poder Judicial, desde un

155 Ibídem, Apdo. 149.

156 Ibídem, Apdo. 158 y ss.

157 Véase, NetTesheim, M., «"Euro-Rettung” und Grundgesetz», en EuR, 2011, pp. 765 y ss., 766 y ss. 
punto de vista institucional, se centra en el Parlamento. Esta cuestión ya fue destacada en la Decisión del Tribunal de Karslruhe en el caso MEDE en el año 2012, no sólo respecto a la seguridad de los elementos de Derecho parlamentario, sino, incluso, en relación con la sensibilidad jurídica frente a las observaciones político-económicas de los legisladores. Los argumentos decisivos en este caso se centraron en puntos clave basados en técnicas de prudencia jurídica, ya sea haciendo énfasis en las prerrogativas de estimacion legislativas, ya sea a través de la aplicación de cautelosos instrumentos de control ${ }^{158}$. Para probar si la autonomía presupuestaria parlamentaria se veía vacía de contenido a través de la celebración de las obligaciones de pago y las declaraciones de responsabilidad, el BVerfG reconoció que se debería garantizar al legislador un «amplio margen de apreciación» «expresamente con vistas a la pregunta de los riesgos de entrada y a las consecuencias, muy esperadas, para la libertad de acción del legislador presupuestario» ${ }^{159}$. Este margen se ha visto ampliado y recoge, especialmente, la «evaluación de la futura viabilidad del presupuesto federal y de los resultados económicos» alemanes, «incluso la consideración de las consecuencias de las opciones alternativas de actuación» ${ }^{160}$. En consecuencia, el BVerfG reconoció al Parlamento, respecto de las potenciales obligaciones financieras de Alemania bajo el MEDE (por un importe que asciende alrededor de los 190 millardos de euros), una amplia prerrogativa de estimación: incluso cuando el análisis coste-beneficios, incluyendo la evaluación de riesgos, fuera una cuestión muy controvertida entre una gran mayoría de expertos economistas, las decisiones del Parlamento no podrían ser clasificadas como incorrectas y ser sustituidas por una propia evaluación del $\mathrm{BVerfG}^{161}$. Esto se corresponde con el criterio de que el BVerfG se limita a la comprobación del cruce de fronteras ${ }^{162}$. Además, también se hace hincapié con total claridad, en el hecho de que el artículo 79.3 GG no garantiza la petrificación del status quo legal, sino que, más bien, garantiza las estructuras y los procedimientos «que mantienen abiertamente el proceso democrático» ${ }^{163}$. El BVerfG aceptó la UEM y, también, consecuentemente el diseño y desarrollo de un proceso de apertura fundamentalmente político de la mano de una prerrogativa parlamentaria de evaluación ${ }^{164}$.

También en otros Estados, en relación con el análisis de la legalidad del MEDE, los ya mencionados Tribunales Supremos y Constitucionales reconocieron

158 BVerfG, MEDE y Pacto Fiscal — Decisión rápida (Nota a pie 26), Apdo. 109, 112 y ss., 118, 124, 130, 167; así como la siguiente BVerfG, MEDE y Pacto Fiscal - Asunto principal (Nota a pie 30), Apdo. 164, 173 y ss., 175, 181, 184 y ss., 216. Véase, también, Tomuschat, C., «Anmerkung zum Urteil des BVerfG vom 12.09.2012», en DVBl., 2012, pp. 1431 y ss., 1434, y KAHL W. (Nota a pie 56), p. 205.

159 BVerfG, MEDE y Pacto Fiscal — Decisión rápida (Nota a pie 26), Apdo. 113.

160 Ibídem.

161 Ibídem., Apdo. 167.

162 Ibídem., Apdo. 112.

163 Ibídem., Apdo. 118.

164 Ibídem. 
a los Parlamentos nacionales una amplia prerrogativa de decisión con vistas al riesgo y a la evaluación del impacto. Esto es así, concretamente, en Austria ${ }^{165}$ y Estonia $^{166}$. Por el contrario, el TJUE practicó un control total con vistas al cumplimiento de las normas de distribución de competencias comunitarias y la prohibición de su realización a través de los Estados miembros en el caso Pringle ${ }^{167}$.

\section{b) El nivel de control frente al BCE}

Para el control de la conformidad legal o constitucional del Programa OMC fue decisiva la pregunta de en qué manera el Poder Judicial estaba dispuesto a conceder márgenes de decisión en determinada medida al comunitariamente diseñado como independiente BCE.

aa) El planteamiento del BVerfG: controles judiciales exhaustivos

Frente a las estimaciones económicas del Banco Central Europeo de las que se percibía poco la moderación racional del BVerfG, el Tribunal de Karslruhe concluyó el principio de la completa revisión de los límites del mandato del $\mathrm{BCE}^{168}$. La Judicial Restraint finalizaba para el BVerfG en el Parlamento, el cual a través de su determinada y constitucionalmente garantizada influencia tiene que responder a la discutida crisis política intergubernamental.

La concesión de un márgen apropiado para el BCE o para el SEBC se impone de forma reconocida directamente. Así, la independencia del BCE será reconocida expresamente en la Ley Fundamental (art. 88.2 GG) como también en el Derecho comunitario (art. 130 TFUE) — este último sólo en la práctica alemana. Sin duda, el postulado de la independencia no puede basarse solo en tener un margen, pues la independencia siempre tiene un tamaño relativo, que se basa en un específico punto de referencia. Así, la independencia se da, ante todo, en relación con la política, es decir, en relación a la inmunización frente a las influencias políticas frecuentemente del Parlamento o de la Administración ministerial. Conforme a su considerción funcional, el BCE es competente, además, de un complejo y dinámico ámbito de actuación, dentro del cual se toman decisiones sobre la base de un pronóstico, las cuales exigen pericia y capacidad para una flexible creación y procesamiento de conocimientos. Por este motivo, se reclama un nivel de control

165 Tribunal Constitucional austriaco, MEDE (Nota a pie 37), Apdo. 57.

166 Tribunal Supremo de Estonia, MEDE (Nota a pie 34), Apdo. 174.

167 En especial, bajo la perspectiva de si los Estados miembros bajo el Derecho comunitario se encuentran impedidos para adherirse a un Tratado como el Tratado-MEDES, véase TJUE, C-370/12 (Pringle), EU:C:2012:756, Apdo. 92 y ss., donde, sin duda, no hay una evaluación de los riesgos ni del impacto.

168 BVerfG, OMC-Petición (Nota a pie 12), Apdo. 58. 
claro y reducido en forma de un márgen de apreciación también para los programas de garantía o de empréstitos del BCE relacionados con la crisis ${ }^{169}$. La consideración ${ }^{170}$ normativa y la funcional participan una en la otra.

El desequilibrio constitucional a favor del Parlamento y en detrimento del BCE resulta clave, y el BVerfG, en sus decisiones más emblemáticas sobre la UE, lo atribuye al principio democrático. Donde la influencia del Parlamento se suprime, brilla a primera vista la necesidad de sostener un más intenso control judicial. Bajo un análisis más preciso, esta conclusión es ciertamente precipitada. Hay que tener en cuenta que un control judicial más estricto sólo tiene lugar en los supuestos en los que el Derecho proporciona criterios suficientemente concretos y que se pueden concretar. Esto es, en vista a las consideraciones macroeconómicas del BCE, algo muy cuestionable. Por ello, el esencial contenido normativo del art. 88.2 GG debe conservar su función de legitimación y modificación a la vista del limitado control democrático de las decisiones del $\mathrm{BCE}^{171}$. Ya en el caso Maastricht el BVerfG clasificó esta norma (con conexión con el art. 79.3 GG) como una modificación del principo democrático, cuya fundamentación resultaba del reconocimiento de la idea «experimentada en el ordenamiento jurídico alemán y, también, acreditada desde una perspectiva científica» de que un Banco central independiente asegura previamente el valor del dinero antes que la política $^{172}$. Pero por este motivo, la independencia del BCE no puede ser introducida de nuevo bajo la apelación al —que constitucionalmente ha dejado huella a través del art. 88.2 GG- principo democrático. La exigencia derivada de la cuestión prejudicial planteada en el caso OMC, de que el mandato del BCE «debería ser firmemente limitado para cumplir con los requisitos democráticos» ${ }^{173}$, es hasta ahora un argumento recurrente.

El BVerfG opinó que la independencia del BCE no imposibilitaba un control judicial sobre la delimitación de sus funciones, lo que podría basarse, sin duda, también en el Derecho comunitario. La asegurada independencia comunitaria del BCE no se opone a un (completo) control judicial, sino que se refiere, sin embargo «sólo a las competencias conferidas al Banco Central Europeo a través de los Tratados y a su configuración interna, pero no a la determinación de la extensión y alcance de su mandato» ${ }^{174}$.

169 Véase, Goldmann, M., «Adjudicating Economics?», en GLJ, 2014, pp. 265 y ss., 266 y ss.; Herrmann, C. (Nota a pie 9), p. 810; Heun, P., «Eine verfassungswidrige Verfassungsgerichtsentscheidung», en $J Z$, 2014, p. 331 (336); BAST, J., (Nota a pie 91), pp. 176 y ss.; KäMmerer, J.A., en SiEKMANN (Ed.), EWU, 2013; art. 123 TFUE, Apdo. 28.

170 Véase, desde el punto vista de la dogmática administrativa, PACHE, E., Tatbestandliche Abwägung und Beurteilungsspielraum, 2001, pp. 69 y ss. y 76 y ss.

171 Pernice, I. en Dreier (Ed.), GG, 2. ${ }^{\text {a }}$ Ed. 2008, Art. 88 GG, Apdo. 26.

172 BVerfG, Maastricht (Nota a pie 54), Apdo. 154, reiterado en BVerfG, OMC-Petición (Nota a pie 12), Apdo. 32.

173 BVerfG, OMC-Petición (Nota a pie 12), Apdo. 58.

174 Ibídem, Apdo. 60. 
bb) El planteamiento del TJUE: el márgen de apreciación en el contexto del test de proporcionalidad

El Tribunal de Justicia fue bien aconsejado, de responder a esta invitación del BVerfG a un control completo con prudencia. Pero el Tribunal de Justicia constató en el caso Gauweiler y otros, ante todo, que esto no excluía la revisión judicial. Dicho de otra forma, la independencia frente al Poder Legislativo no significa ninguna exención de control en relación al Poder Judicial. Un control de este tipo tiene, especialmente, que asegurar el cumplimiento del principo de atribución de competencias y centrar el análisis en el hecho de que el SEBC permanezca dentro de los límites de las competencias atribuidas al mismo por el Derecho primario ${ }^{175}$. En el marco de la concreta prueba de si el OMC era idóneo para impulsar los objetivos de la política monetaria del BCE - lo que conforme a la dogmática del TJUE, pertenece al test de proporcionalidad-, el TJUE concedió al BCE, sin embargo, «un amplio márgen de discrecionalidad» ${ }^{176}$, basado, en esencia, en consideraciones funcionales. El SEBC se mueve en el marco de las operaciones de mercado abierto y aquí toma «decisiones de naturaleza técnica»y debe efectuar «complejos pronósticos y evaluaciones» ${ }^{177}$. Cuando la dogmática jurídica plantea preguntas localizadas, la concesión de un margen de apreciación convence en el resultado. La base jurídica para las operaciones de mercado abierto (art. 18.1 Estatutos SEBC) se estructura finalmente y presupone de hecho «la consecución de los objetivos del SEBC», los cuales se inspiran en el art. 127.1 y 282.2 TFUE. Pero la evalución de la adecuación de los objetivos requiere necesariamente de estimaciones económicas y pronósticos sobre los efectos reales de las medidas, que se mueven en un entorno material altamente complejo y en un cambio dinámico continuo. Sin embargo, no se trata de una exención total del control judicial, como el BVerfG había sugerido como alternativa, sino que se trata del reconocimiento de amplios márgenes de apreciación ${ }^{178}$.

El TJUE perfila el alcance del márgen de apreciación poniendo el acento en el esencial significado de las garantías procesales, para lo que cuenta, en especial, con las exigencias de motivación y las obligaciones de un diligente e imparcial examen de todos los aspectos relevantes del caso $^{179}$. La acentuación de los requisitos procesales corresponde a los principios clásicos de un control del márgen, como lo conocen a nivel nacional. En lugar de un completo control judicial, el

175 TJUE, C-62/14 (Gauweiler y otros), EU:C:2015:400, Apdo. 40 y ss.

176 Ibídem, Apdo. 68.

177 Ibídem.

178 El TJUE no diferenció terminológicamente entre un (material) márgen de apreciación y una (jurídica) discrecionalidad. Al respecto, DANwiTz, T.v., Europäisches Verwaltungsrecht, 2008, pp. 361 y ss.

179 TJUE, C-62/14 (Gauweiler y otros), EU:C:2015:400, Apdo. 69. 
TJUE optó así por «una función de adecuación de pesos y contrapesos» ${ }^{180}$. Sobre esta premisa, el TJUE llegó al convincente resultado de que la evaluación del SEBC alteraba el mecanismo de transmisión de la política monetaria y debía ser corregido, aunque en ningún caso «estaba afectado por un manifiesto error de apreciación» ${ }^{181}$. Con vista al «amplio márgen de discrecionalidad» del SEBC y de la percepción de que «las cuestiones de política monetaria suelen ser controvertidas», no podría requerirse del SEBC más que el uso de su experiencia económica y la disponibilidad del necesario medio técnico (...), para realizar este análisis con toda la precaución y precisión» ${ }^{182}$. El TJUE ha entendido que esta era la forma más convincente para llevar a cabo un control de competencias y, al mismo tiempo, no colocar su propio análisis económico en el lugar del efectuado por el, independiente y equipado con conocimientos especializados, BCE. En el tratamiento del márgen de apreación la sentencia Gauweiler y otros del TJUE supone un caso ejemplar tanto a nivel de criterios como también a nivel de la técnica de la subsunción o de calificación de los hechos.

\section{Los criterios de control ante el BVerfG y el TJUE}

Por último, son de suma importancia las decisiones emblemáticas relacionadas con la crisis para el futuro de la UEM porque ayudan a perfilar, de una forma más detallada, las normas clave de distribución de competencias y las normas jurídicas materiales.

a) Consideración previa: los fenómenos de estratificación como un desafio clave para el pluralismo constitucional

Los criterios jurídicos seguidos por el TJUE no son en esencia los del BVerfG. No obstante, ya ha quedado claro en numerosos aspectos, que los existentes mecanismos de separación en principio, con frecuencia, se rompen. Así, a menudo, son relevantes y necesarias medidas jurídicas de Derecho comunitario a aplicar en los procedimientos constitucionales —más allá incluso de patológicas situaciones específicas como la activación de la «reserva de necesidad (o subsidiariedad)»La actual discusión sobre los derechos fundamentales europeos a nivel federal muestra, con total claridad, la renuncia a la «tesis de la separación» o a la «tesis de la alternatividad», a lo que se une la idea de seguir el correcto camino de la

180 Así se encuentra, Classen, C.D., «Funktionsadäquate checks and balances statt richterlicher Vollkontrolle unter demokratischem Vorwand», en $E u R, 2015$, pp. 477 y ss. (en especial, 480 y ss.).

181 TJUE, C-62/14 (Ganweiler y otros), EU:C:2015:400, Apdo. 74. Sin embargo, crítica, BVerfG, OMC-Sentencia final (Nota a pie 19), Apdos. 184, 190.

182 TJUE, C-62/14 (Ganweiler y otros), EU:C:2015:400, Apdo. 75. 
estratificación de los criterios jurídicos diferenciados por niveles ${ }^{183}$. El verdadero reto de crear cooperativamente un pluralismo constitucional europeo se encuentra no tanto en la heurística detección de la separación de las esferas, sino mucho más allá, en el procesamiento normativo del fenómeno de superposición y del fenómeno de estratificación desde la respectiva perspectiva de ordenamientos jurídicos autónomos e independientes unos de otros. Se trata, en otras palabras, del (posterior) desarrollo de técnicas jurídicas compuestas, que hacen —a pesar de que sólo una parte del Derecho del ordenamiento juíridico es autónomo- que el respectivo ordenamiento jurídico sea permeable ${ }^{184}$.

\section{b) El título competencial y el ejercicio de los límites competenciales}

Si se trata de analizar los fundamentos competenciales de la UEM, tanto el BVerfG como el TJUE muestran puntos de vista con divergencias significativas.

aa) El título competencial: acercamiento normativo al mandato del BCE

Mientras el BVerfG vió el mandato del BCE a través del Programa OMC como manifiestamente sobrepasado, el TJUE consideró que se respetaba el cumplimiento del marco competencial del Derecho originario. Un problema central del control ultra-vires se encuentra en sus híbridos estándares de revisión, pues toma su punto de partida en el Derecho constitucional y finaliza, sin embargo, en el Derecho comunitario. La consecuencia es una específica interpretación propia del Derecho de la Unión, una imagen distorsionada del comunitario sistema de competencias visto a través de las gafas de la Ley Fundamental. La consecuencia es que se produce una diferencia en las opiniones jurídicas del TJUE y las del BVerfG no sólo a nivel de subsunción, sino también en el uso de los criterios en relación con las premisas sobre las respectivas competencias. Para el BVerfG la decisiva prueba de fuego era ver si el Programa OMC «invade las competencias de los Estados miembros en materia de política económica» ${ }^{185}$. Con esta premisa,

183 Véase, KIngreen, T., «Die Grundrechte des Grundgesetzes im europäischen Grundrechtsföderalismus», en $J Z, 2013$, pp. 801 y ss., 802 y ss., el cual limita en el contexto de la Teoría de la acumulación y la alternativa del caso Akerberg Fransson (elegida por el TJUE); THYM, D., «Vereinigt die Grundrechte!», en $J Z, 2015$, pp. 53 y ss., 55 y ss., con la clasificación entre la Tesis de la separación y la doble validez; Franzius, C., «Strategien der Grundrechtsoptimierung in Europa», en EuGRZ, 2015, pp. 139 y ss., 140 y ss.; MASING, J., «Einheit und Vielfalt des Europäischen Grundrechtsschutzes», en JZ, 2015, pp. 477 y ss., 485 y ss., el cual señala que la aplicación paralela de los derechos fundamentales nacionales y los de la Unión es sólo la «segunda mejor» opción.

184 WeNDEL, M. (Nota a pie 5), pp. 7 y ss.

185 BVerfG, OMC-Petición (Nota a pie 12), Apdo. 55, así como previamente, Apdo. 33, 39 y Cuestión 1 lit. a). 
el Tribunal de Karlsruhe retorció el criterio de revisión empleado en la Sentencia Pringle. A causa del consiguiente efecto de bloqueo, derivado del art. 2.1 TFUE, el TJUE había preguntado, de forma acertada en el caso Pringle ${ }^{186}$, si la construcción del MEDE a través de la actuación de los Estados miembros, se encontraba incluída en la competencia exclusiva de la Unión relativa a la política monetaria $^{187}$. Y, por lo tanto, si, por el contrario, se desarrollaron competencias económicas de los Estados miembros en el ámbito de la política económica, pero materialmente con ningún efecto de bloqueo en contra de la Unión ${ }^{188}$. Conforme a los Tratados, la práctica está ligada a una reconocida competencia de la Unión, pero no está vinculada negativamente a una categoría de competencias «exclusivas» de los Estados miembros. Esta consideración de incorporar en los Tratados un catálogo negativo de exclusivas competencias nacionales se rechazó en el pasado, incluso, de forma expresa ${ }^{189}$. No obstante, el BVerfG reconoció, desde la perspectiva del reconstruido ordenamiento competencial de la Unión Europea, un domaine réservé de política económica para los Estados miembros ${ }^{190}$.

$\mathrm{El}$ actual fundamento para las operaciones de mercado abierto recogido en el artículo 18.1 de los Estatutos del SEBC no realiza ninguna diferenciación jurídica en función del dual concepto de política monetaria y económica. Mucho más, asume objetivamente, que el BCE realiza la política de mercado abierto «para conseguir los objetivos del SEBC y para llevar a cabo sus funciones». El objetivo prioritario del SEBC es la garantía de la estabilidad de los precios (art. 127.1.1, art. 282.2.2. TFUE) ${ }^{191}$, mientras que un objetivo secundario es el apoyo a las políticas económicas generales en la Unión (art. 127.1.2, art. 282.2.3 TFUE). Por mandato de la política monetaria del BCE, en el sentido de los Tratados, se incluye también el apoyo a la política económica, en la medida de lo posible, sin comprometer el objetivo principal de la estabilidad de precios. Consecuentemente, el BCE debe ser, a través de las operaciones de mercado abierto también activo económicamente, cuando con ello puede así conseguir sus objeti$\operatorname{vos}^{192}$. La cuestión de la legalidad e ilegalidad de una medida de la política de mercado abierto no está correlacionada con la dicotomía conceptual de la política económica y monetaria. Además, a esto se añade la dificultad de que ambos

186 Sin embargo, sin citar explícitamente la norma, véase, Abogado General, en el caso Kokott, Dictamen (sic.) de 26.10.2012, C-370/12 (Pringle), EU:C:2012:675, Apdo. 75.

187 TJUE, C-370/12 (Pringle), EU:C:2012:756, Apdos. 93-98.

188 Véase, BAST, J. (Nota a pie 91), p. 176.

189 Para esta discusión en el marco de las Asambleas constituyentes, más de cerca, GuASTAFerro, B., «Beyond the Exceptionalism of Constitutional Conflicts», Jean Monnet Working Paper 01/12, pp. 16 y ss., sin embargo, la cláusula de identidad se mueve en el marco de una cláusula de salvaguardia para algunas competencias básicas de los Estados miembros. Incluso si se sigue esta interpretación del art. 4.2 TUE, se cubre el ámbito de la política económica, pero no los ámbitos ya citados en la cláusula de la identidad.

190 BVerfG, OMC-Petición (Nota a pie 12), Apdo. 39.

191 En particular, Thiele, A., Das Mandat der EZB und die Krise des Euro, 2013, pp. 24 y ss.

192 Véase, Heun, W. (Nota a pie 168), p. 333. 
ámbitos finalmente están interrelaccionados inseparablemente. Después de la intervención del Abogado General, Cruz Villalón, se mantiene la necesidad de la separación de ambos ámbitos, «de la estructura de los Tratados y de la distribución de competencias horizontal y vertical en la Unión», a lo cual desde un punto de vista económico dejó decir que «finalmente cada medida de política monetaria cae en la categoría más amplia de la general política económica» ${ }^{193}$. El TJUE reconoció esta conexión intrínseca, al menos indirectamente, a través de la constatación de que una medida de efectos indirectos en un ámbtio puede tener efectos en el otro ${ }^{194}$. La pertinencia de la separación categórica es también limitada - tanto económica como normativamente-.

Sobre los niveles de referencia, el TJUE viene al encuentro del BVerfG, ahora, al menos, con la constatación de que el SEBC no debería «de forma válida acordar un Programa y aplicarlo si va más allá del ámbito que le es asignado de la política monetaria a través del Derecho originario», sobre el que el TJUE tiene competencia para garantizar ${ }^{195}$. De aquí se sigue, sin duda, no a la inversa, que las medidas de política económica se encuentran per se fuera del mandato del BCE. Así, el TJUE señala también en consecuencia, muy claramente, que, conforme a los Tratados, incluso el respaldo de las políticas económicas generales pertenece a la política monetaria, en la medida en que esta última no afecte a la estabilidad de precios ${ }^{196}$. De acuerdo con esto, para que se produzca la imputación de una actividad a la política monetaria, depende en primer lugar, de la finalidad ${ }^{197}$. Esta argumentación le funcionó al TJUE en el asunto Gauweiler y otros, y así posteriormente la aplicó al Programa OMC al que situó de una manera convincente en el ámbito de la «política monetaria», en el sentido anteriormente descrito.

También al nivel de la subsunción, el TJUE llegó a una conclusión totalmente diferente a la alcanzada por el BVerfG, el cual había calificado el Programa OMC como una medida predominantemente de política económica. Para la clasificación del Programa OMC, a la vista del Tribunal de Justicia, el citado objetivo del BCE es llevar a cabo una adecuada transmisión de la política monetaria de vital trascendencia ${ }^{198}$. Una alteración del mecanismo de transmisión de la política monetaria es la actuación «idónea para dejar caer en

193 Abogado General, Cruz Villalón, Conclusiones generales, de 14.1.2015, C-62/14 (Ganweiler y otros), EU:C:2015:7, Apdo. 129.

194 TJUE, C-370/12 (Pringle), EU:C:2012:756, Apdo. 56; C-62/14 (Ganweiler yotros), EU:C:2015:400, Apdo. 51 y ss., 59 y 109 y ss.

195 TJUE, C-62/14 (Ganweiler y otros), EU:C:2015:400, Apdo. 41.

196 Ibídem, Apdos. 43, 59.

197 Ibídem, Apdo. 46, sobre la naturaleza de los medios empleados sólo en segundo lugar. Esto tiene también sentido al comprobar los hechos descritos en el art. 18.1 Estatutos del SEBC, como se ha visto, por su parte, en los objetivos del SEBC, por lo que con la certeza de que el BCE ha recurrido en forma de operaciones de mercado abierto a medios de política económica del Derecho originario (así, por ejemplo, ibídem Apdo. 54), en realidad finalmente no se ha ganado mucho.

198 Ibídem, Apdos. 49-52. 
el vacio la decisión del SEBC en una parte de la garantizada zona euro, y para perjudicar a la unidad de la política monetaria», lo que entonces, inevitablemente, también acaba afectando a su capacidad para garantizar la estabilidad de los precios ${ }^{199}$. Por el contrario, el BVerfG habría dado ventaja, desde su punto de vista, a la «convicente experiencia» del Banco Federal alemán ${ }^{200}$. El objetivo planteado por el BCE es jurídicamente irrelevante porque la mera circunstancia de comprar deuda soberana «bajo circunstancias, podría también contribuir», a respaldar los objetivos de política monetaria, a pesar de que el Programa OMC todavía no lo califica como una medida política monetaria ${ }^{201}$. Así, el BVerfG probó no sólo lo que había asumido previamente de manera implítica, sino que probó expresamente las premisas (económicas), por las que las compras de bonos anunciadas también «bajo determinadas ciscunstancias» tenían efectos de política monetaria, con lo que demostró, en fin, que su carácter políticamente económico era secundario. Esta evaluación sobre los reales efectos de las medidas la colocó el BVerfG enfrente del diferente análisis económico efectuado por el BCE. Por el contrario, como ya se ha indicado ${ }^{202}$, el TJUE reconococió al BCE un amplio márgen de discrecionalidad, al cual le correspondía un reducido control judicial. Un evidente error de apreciación no sería para el TJUE reconocible ${ }^{203}$. El SEBC podría «llegar a la evaluación legítimamente» realizada de que un Programa como el OMC «es adecuado para contribuir a los consiguientes objetivos del BCE y para garantizar la estabilidad de los precios» ${ }^{204}$.

El TJUE presentó sus argumentos convencido también a la vista de los aspectos centrales de la condicionalidad. El BVerfG había clasificado el Programa OMC, especialmente, como una medida principalmente de política económica porque el mismo partía de la condicionalidad del Programa de ayuda y, además, porque desde el punto de vista del BVerfG, establece un funcional, aunque no equivalente, control parlamentario para el Mecanismo Europeo de Estabilidad (MEDE) y el Fondo Europeo de Estabilidad Financiera $(\mathrm{FEEF})^{205}$. Más convincente fue, sin embargo, a sensu contrario: la conexión a las condiciones del Programa de ayuda, lo que probaba que el SEBC no desarrollaba ningúna política económica independiente, sino que se limitaba, a través de la asunción de las obligaciones de su mandato, a la correspondiente mera ayuda de la política económica ${ }^{206}$. A través de la referencia a las limitaciones

199 Ibídem, Apdo. 50.

200 BVerfG, OMC-Petición (Nota a pie 12), Apdo. 71.

201 Ibídem, Apdo. 96.

202 Véase, V.1.b.

203 TJUE, C-62/14 (Ganweiler y otros), EU:C:2015:400, Apdo. 74.

204 Ibídem, Apdo. 80.

205 BVerfG, OMC-Petición (Nota a pie 12), Apdo. 79.

206 Se puede ver en BAST, J. (Nota a pie 91), p. 178. 
macroeconómicas del paquete de rescate, el SEBC asumía finalmente las deciciones tomadas por los Estados miembros en el Consejo de gobierno del MEDE (compárese art. 13 Tratado MEDE), las cuales a su vez, están sujetas a control parlamentario y responsabilidad a nivel nacional. En Alemania se aplica conforme a la jurisprudencia elaborada por el $\mathrm{BVerfG}^{207}$ - la reserva parlamentaria ${ }^{208}$. Tras esta lectura, el BCE debe partir, más bien, de la condicionalidad de los Programas de ayuda para avanzar en el marco de su mandato contractual. Mientras el Abogado General criticó el doble rol del BCE, por un lado, por su participación en la negociación y, posteriormente, el seguimiento del Programa de reforma, y, por otro lado, por la elaboración del Programa $\mathrm{OMC}^{209}$, el TJUE concluyó de esta lectura, que el SEBC a través de la conexión con dicha condicionalidad, podría evitar perjudicar la efectividad de las medidas de rescate de las que son responsables los Estados miembros (en términos de política económica ${ }^{210}$.

Al mismo tiempo, el TJUE efectuó una convincente distinguishing del caso Pringle. Dejó claro que no era suficiente, por sí solo, para la legitimidad de un Programa como el OMC, que los Estados miembros afectados respetaran las condiciones del Programa de reforma, sino que, a causa de la finalidad de garantía política, también deberían tener en cuenta y contar con las reales alteraciones de los mecanismos de transmisión de política económica o de la unidad de la política económica ${ }^{211}$.

bb) La competencialmente limitada proporcionalidad

En las declaraciones del TJUE, el principio de proporcionalidad cobra un papel fundamental. A primera vista, no carece de una cierta ironía que el principio de proporcionalidad — destacado testimonio de la exportación constitucional alemana - ni en la cuestión prejudicial del BVerfG ni en las numerosas aportaciones doctrinales de origen alemán juega un papel notable, pero, por otro lado, en cierto modo, domina una parte central de la Sentencia del TJUE. Considerándolo más detenidamente, surgen también las dudas de si el principio de proporcionalidad, en su función como límite competencial (art. 5.4 TUE), es el instrumento más decuado dogmáticamente para (abordar) la dirección jurídica de las relevantes cuestiones aquí planteadas.

207 Véase BVerfG, MEDE y Pacto Fiscal - Decisión rápida (Nota a pie 26), Apdo. 170, así como BVerfG, - Asunto principal (Nota a pie 28), Apdo. 217.

$208 \S 4.1 .1,2$ en relación con el apartado 2 de la Ley de Financiación-MEDE.

209 Abogado General Cruz Villalón, Conclusiones generales, de 14.1.2015, C-62/14 (Gauweiler y otros), EU:C:2015:7, Apdos. 142-151.

210 TJUE, C-62/14 (Ganweiler y otros), EU:C:2015:400, Apdo. 60.

211 Ibídem, Apdos. 62-64. 
Así es la cuestión de la adecuación de objetivos del Programa OMC, lo que el TJUE somete en el marco de un control de idoneidad ${ }^{212}$, que en última instancia es una pregunta sobre la pertinencia fáctica del fundamento competencial, lo que, precisamente, en último término, muestra una estructura normativa. El TJUE, sin embargo, acordó su revisión. Con vistas al mandato «de política monetaria» del BCE, el Tribunal de Justicia examinó por primera vez, de forma abstracta, si el objetivo de garantizar una adecuada transmisión de la política económica era atribuible, de por sí, a la política monetaria ${ }^{213}$. En el marco de la proporcionalidad, el Tribunal de Justicia probó después si el Programa OMC era adecuado, también concretamente, para conseguir esos objetivos ${ }^{214}$. Sólo para la segunda etapa de la prueba, el TJUE valoró su nivel de control con vistas al márgen de apreciación económico del $\mathrm{BCE}^{215}$.

En el marco de criterio de necesidad, el Tribunal de Justicia señaló, también, límites legales del Programa OMC desde un punto de vista final, material, situacional y temporal ${ }^{216}$, y proclamó el selectivo carácter del Programa OMC como una manifestación de la necesidad ${ }^{217}$. Estas apreciaciones supusieron apuntar un nuevo tanto para el BVerfG, que las elaboró correctamente ${ }^{218}$. Aquí, el BVerfG, en parte, sobrepasa, más o menos, la Sentencia Ganweiler, cuando extrae de lo anterior una obligación de fijar una volumétrica limitación de las adquisiciones, la cual no había sido sido formulada ${ }^{219}$.

En ambos casos, tanto la prueba de la adecuación de objetivos en el marco de una prueba de idoneidad, así como la formulación de los límites jurídicos en el marco de un criterio de necesidad, habrían podido efectuarse de forma indirecta conforme al artículo 18.1 Estatutos SEBC. Después de todo, no se trata de una cuestión diferente a si y, eventualmente, en qué medida, una medida atípica como el Programa OMC puede encajarse finalmente en una estructurada fundamentación jurídica, en una norma jurídica. En lugar de adaptar la cuestión al Derecho primario sobre la relación entre la Unión y los Estados miembros ${ }^{220}$, y, en este sentido, consultar al principio federativo de proporcionalidad conforme al art. 5.4 TUE, no se ofrece ningún valor añadido visible al caso ${ }^{221}$. Que la utilización de los mencionados aspectos convenza poco dogmáticamente para un juicio

212 TJUE, C-62/14 (Ganweiler y otros), EU:C:2015:400, Apdos. 72-80.

213 Ibídem, Apdos. 49-52.

214 Ibídem, Apdos. 72-80.

215 Ibídem, Apdo. 68 y ss.

216 No se puede entrar aquí a profundizar sobre el tema. Véase, en particular, ibídem, Apdos. 82-87.

217 Ibídem, Apdo. 89 y ss.

218 BVerfG, OMC-Petición (Nota a pie 12), Apdo. 199.

219 Ibídem. Con referencia al TJUE, C-62/14 (Gauweiler y otros), EU:C:2015:400, Apdo. 106, donde no está disponible.

220 Véase, Calliess, C., en Calliess / Ruffert (Eds.), EUV/AEUV, 4. ${ }^{a}$ Ed., 2011, Art. 5 TUE, Apdo. 55

221 Así, también, Classen, C.D. (Nota a pie 179), p. 482. 
de proporcionalidad, se muestra, por otra parte, exclusivamente en la sencilla prueba de idoneidad. No está todavía claro qué «intereses implicados» debería tener aquí el BCE y de qué forma y manera deberían ser «recíprocamente considerados cuidadosamente». Por supuesto, el planteamiento del TJUE permite al BVerfG, a través del reconocimiento de un control completo con vistas al cumplimiento del principio de distribución de competencias a nivel de título competencial, mostrarse complaciente, pero al mismo tiempo, reducir el nivel de control en relación con el criterio de idoneidad, y reducir los límites sobre la necesidad. Así, siendo esta construcción cuestionable dogmáticamente, se rechaza el argumento del TJUE en el panorama general, pero la narrativa jurídica muestra de una forma clara que en la crisis se ha roto el (sistemático) Derecho comunitario.

\section{CONCLUSIÓN Y PERSPECTIVA}

En líneas generales, el BVerfG, con su cuestión prejudicial al caso OMC, se ha enfrentado a muchas zonas fronterizas constitucionales y comunitarias. En un esfuerzo por garatizar el Derecho y la democracia, el Tribunal constitucional caminó por una expectante cresta cada vez más estrecha. Que el Tribunal constitucional desde aquí encontrara nuevamente el camino de vuelta a tierra firme, dependió en gran medida de que el TJUE le echara una mano.

Pero el ejemplo del caso OMC muestra también, al mismo tiempo, que la interacción cooperativa de las instancias de control a nivel nacional y comunitario es todavía mejorable. La cuestión presentada ante el TJUE le como si fuera un exceso del ámbito procesal constitucional no correspondió ni en su tono ni en término de axiomas fundamentales a un control ultra vires propio de la constructiva introducción de un diálogo multinivel. Por lo tanto, la respuesta del TJUE también fue materialmente diferenciada y en un tono sobrio y comedido. Que los Jueces del Segundo Senado hayan adoptado la posibilidad que se les ofrecía en la sentencia Gauweiler, a pesar de que en algunos puntos no compartían la opinión de sus colegas de Luxemburgo, es a modo de conclusión, pero también, una evidencia del necesario cumplimiento de la distribución de competencias en una unión de Tribunales europeos.

La saga del caso OMC ilustra cuál es el papel central que juega el reconocimiento recíproco de márgenes de apreciación. La concesión multinivel de márgenes de apreciación es una de las técnicas decisivas que aseguran la viabilidad de funcionamiento de una unión de Tribunales comunitarios. El TJUE y el BVerfG se confiesan mutuamente - y por sus respectivos ámbitos competencialesdecisiones o márgenes de apreciación, ya sea con vistas a la clasificación constitucional federal de la propuesta, ya sea respecto de la autonomía del TJUE vinculado a los métodos tradicionales de interpretación del Derecho comunitario de los Estados miembros. Fue el Abogado General, Cruz Villalón, el que recordó con diplomática cautela una cierta decisión estratégica conseguida por el Tribunal de 
Karlsruhe ${ }^{222}$. Conforme al mimo, no es «tarea del Tribunal constitucional federal alemán, por problemas de interpretación del Derecho comunitario, que podrían conducir a diferentes resultados por una interpretación metódica de la ley en el habitual marco de discusión jurídica, sustituir con su propia interpretación a la del Tribunal de Justicia» ${ }^{223}$. Esto fue, sin duda, una buena noticia para todos los interesados, que el BVerfG sostuvo como decisión estratégica y que no maniobró hacia una vía muerta.

TITLE: The German Federal Constitutional Court between juridical Protection and competency Excess. The Effectiveness of national constitutional Controls in times of european Crisis

Aвstract: The crisis places the Law before litmus tests. Precisely, the economic and financial crisis can be counted from all points of view as a type of story about the existing federal level of tension, which will be reflected in the pronouncements of the highest judicial spokesmen, who play here a leading role. A clear example of this tension is analyzed in this paper, where, having as background the controversy that arose between the German Federal Constitutional Court and the Court of Justice of the European Union in the thread of analyzing the legitimacy of a Programm of the Central Bank of European Union to combat the crisis, questions are raised regarding the effectiveness of national constitutional checks in times of European crisis.

Resumen: La crisis sitúa al Derecho ante importantes pruebas de fuego. Precisamente, la crisis económica y financiera permite ser contada, desde todos los puntos de vista, como un tipo de relato sobre el nivel de tensión federal existente, que se va a ver reflejado en los pronunciamientos de los más altos portavoces judiciales, que juegan aquí un papel destacado. Un claro ejemplo de esta tensión se analiza en este trabajo, donde, teniendo como telón de fondo la controversia que surgió entre el Tribunal Constitucional Federal alemán y el Tribunal de Justicia de la Unión Europea al bilo de analizar la legitimidad de un Programa del Banco Central Europeo destinado a combatir la crisis, se plantean cuestiones relacionadas con la eficacia de los controles constitucionales nacionales en los tiempos de crisis europea.

KeY wORDs: Control of constitutionality, European Crisis, Distribution of competences, Constitutional Courts, Constitucional pluralism, German Federal Constitutional Court.

Palabras Clave: Control de constitucionalidad, Crisis europea, Distribución de competencias, Pluralismo constitucional, Tribunales constitucionales, Tribunal constitucional federal alemán.

FECHA DE RECEPCIÓN: 15.01.2017

FECHA DE ACEPTACIÓN: 02.02.2017

222 Abogado General, Cruz Villalón, Conclusiones generales, de 14.1.2015, C-62/14 (Gauweiler y otros), EU:C:2015:7, Apdo. 67.

223 BVerfG, Honeywell (Nota a pie 80), Apdo. 66, ya repetido en BVerfG, OMC-Sentencia final (Nota a pie 19), Apdo. 161. 